\title{
European Journal of Geosciences
}

https://www.euraass.com/article/category/list-of-journals/ejgs

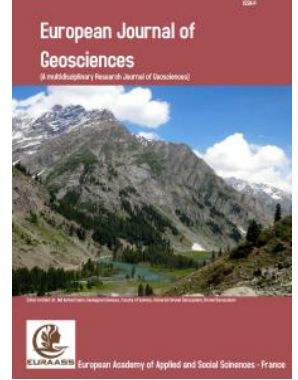

\section{Research Article}

\section{Spatiotemporal variability of rainfall linked to ground water level under changing climate in northwestern region, Bangladesh}

\section{Fatematuz Zannat ${ }^{a}$, A.R.M. Towfiqul Islamª, ${ }^{\mathrm{a},}$, M. Atiqur Rahman ${ }^{\mathrm{c}}$}

\author{
${ }^{a}$ Department of Disaster Management, Begum Rokeya University, Rangpur 5400, Bangladesh \\ ${ }^{b}$ Disaster Management E-learning Centre, Begum Rokeya University, Rangpur 5400, Bangladesh \\ ${ }^{c}$ Department of Geography and Environmental Studies, University of Chittagong, Chittagong 4331, Bangladesh
}

Received: 09 November 2018 / Revised: 12 February 2019 / Accepted: 24 March 2019

\begin{abstract}
Bangladesh is one of the most climatic hazard-prone countries in the world. Rainfall in Bangladesh is highly variable which depends on each season and location. This study aims to investigate spatiotemporal variability of rainfall linked to groundwater level under changing climate in the northwestern region, Bangladesh during the period of 1976-2016 using rainfall and groundwater level data. A number of statistical approaches such as Mann-Kendall (MK) test, linear regression model, Sen's slope estimator and Spearman's rho (SK) test, Coefficient of Variation (CV) were employed to reveal trends and variability of rainfall and groundwater level. Additionally, wavelet transform was applied to assess temporal variability of rainfall time series in the northwestern region, Bangladesh. The results show that the annual rainfall variability was the highest in the Ishwardi station (25.39\%) and the lowest was found in Rajshahi $(20.70 \%)$. The MK test results reveal that the trends of annual and seasonal rainfall decreased gradually, where the highest significant decreasing trend of annual rainfall was found in Rajshahi $(-2.976 \mathrm{~mm} / \mathrm{year})$ and the lowest decreasing trend was found in Syedpur (-1.278 $\mathrm{mm} /$ year). Furthermore, monsoon and winter seasons represent the decreasing trends of rainfall for all the stations. The results of wavelet analysis demonstrate that the monthly rainfall variance of average rainfall in the northwestern region was low from the period of 2006 to 2014, indicating the dry years. The annual and seasonal rainfall trends in the northwestern region were decreased, particularly in the recent decade. The relationship between rainfall and groundwater level indicates that rainfall was decreased and the ground water level was also declining at the same time in the study region. Interestingly, it is observed that a significant high decreasing trend of annual rainfall is found in Rangpur but the annual groundwater level depth is less increased in Rangpur at the same time.
\end{abstract}

\section{Keywords:}

Rainfall variability, Spatio-temporal trend, Wavelet transform, Groundwater level, Northwest Bangladesh.

(c) Euraass 2019. All rights reserved.

\section{Introduction}

Global rainfall patterns are being changed due the climate change impacts and in Bangladesh the climate is changing more unpredictably in recent years (Ahammed et al., 2014). Various research studies indicate that global warming is responsible to climate change and for this rainfall has reformed resulting in frequent extreme weather events (Briffa et al., 2009; Zhang et al., 2009). The

*Corresponding author: E-mail: towfiq_dm@brur.ac.bd (A.R.M. Towfiqul Islam).

Available online: 12 April 2019;

DOI: https://doi.org/10.34154/2019-EJGS-0101-35-56/euraass

Journal reference: Eur. J. Geosc. 2019, 01(01): 35 - 56.

ISSN-E: 2677-643X

(C) European Academy of Applied and Social Sciences. Euraass - 2019. All rights reserved.

Cite as: Zannat, F., Islam, A. R. M., \& Rahman, M. A. (2019). Spatiotemporal variability of rainfall linked to ground water level under changing climate in northwestern region, Bangladesh, Eur. J. Geosc. 2019, 01(01) $35-56$. 
Intergovernmental Panel on Climate Change (IPCC) has accepted that climate change issue is an established fact in recent years and it is a threat to sustainable development (Fatima Denton 2013).

Bangladesh is one of the most vulnerable countries in the world experiencing different types of natural hazards almost every year due to the impacts of climate change (Ahammed et al., 2014). Rainfall dominated the climate of Bangladesh which remains high during the seasons of summer, monsoon and low in the remaining period of years. Bangladesh experiences a tropical monsoon climate (Rahman et al., 2015). The rainy season occurs during the monsoon from June to September, with heavy and frequent rainfall caused by low pressure weather systems from the Bay of Bengal. In some places of this country, the maximum temperature in summer season rises up to $35^{\circ} \mathrm{C}$ or more. Temperature decreases slightly with the rainy season (Banglapedia, 2003). The climate of northwestern region, Bangladesh is humid. This region is well known for its weather extremes. Rainfall in this area is erratic and low with an average value of $1483 \mathrm{~mm}$ per year (Rahman et al., 2016).

In Bangladesh, a few studies were carried out on rainfall trend and variability (Bari et al., 2016; Choudhury et al., 2013; Ahasan et al., 2010; Ahmed and Kim, 2003). However, they do not clearly signify the spatial and temporal trend of rainfall and their variation over time for different climatic regions of Bangladesh, especially for the northwestern region. Rahman et al., (2016) analyzed rainfall trend over Bangladesh where in annual rainfall increasing trends were found for Cox's Bazar, Satkhiraand Khulna and the decreasing trends was found in Srimangal areas. For monthly rainfall Comilla had decreasing trend where Rangpur and Khulna had increasing trends. Ahasan et al., (2010) analyzed variability and trends of summer monsoon rainfall over Bangladesh in which the average monsoon rainfall trend was decreasing. The summer monsoon rainfall exhibits increasing trends in the northwestern region and in the south-central and extreme in the southeastern region. Mirza et al., (2010) studied trends and persistence in precipitation where a significant increase in annual and pre-monsoon rainfall was found in the Ganges, Brahmaputra and Meghna river basins, Bangladesh. Hossain et al., (2010) studied spatial and temporal variability of rainfall over the south coast of Bangladesh where the trend of mean annual rainfall was increased. Pre-monsoon and monsoon rainfall had decreased. The post-monsoon and winter rainfall trends increased in south coast region, Bangladesh. Choudhury et al., (2013) analyzed seasonal variations of temperature and rainfall characteristics in the northeastern part of Bangladesh. The annual rainfall was decreased in the northwestern region except Rangpur and the pre-monsoon and monsoon rainfall had decreasing trends in the northwestern region. However, no research was found on rainfall variability for northwestern region, Bangladesh. This part of Bangladesh represents the most climatic subdivisions and covers the wettest and the driest parts of the country (Bari et al., 2016). Drought frequency in Bangladesh has increased in recent years, particularly in the northwestern region (Adhikari et al., 2013). In some parts of Bangladesh, it is a recurrent phenomenon, but the northwestern region is severely drought prone because of the high variability in rainfall (Shahid and Behrawan, 2008).

Due to the effects of climatic variability and climate change this region's agriculture-based economy, economic developments, water and food security are highly vulnerable. For the contribution to crop water demand on agricultural production, rainfall has the highest impact than other climatic factors (Islam et al., 2009). Agricultural practices in the northwestern region in Bangladesh are mainly dependent on rainfall and ground water. In this region's ground water based irrigation system, ground water provides about $75 \%$ water for irrigation (Sarkar and Ali 2009; Bari et al., 2000). The groundwater based irrigation system in the northwestern region has reached a critical stage as the water level has dropped below shallow wells in many places (BADC 2005). The northwestern region has been experiencing belowaverage rainfall that is the cause of lowering the ground water levels in aquifers which leading to water crisis for industry, household and agriculture in this region. Various statistical methods are now frequently used by researchers for analyzing variability and trends (Kozak, 2008; Ye et al., 2017; Meshram et al., 2016; Shahid, 2010), the non-parametric test gives much proper result than the parametric test. In this study the spatiotemporal analysis of rainfall variability and trend are done for the northwestern region, Bangladesh and the potential causes of rainfall variation are also discussed. To detect the variations in rainfall, coefficient of variation (CV) was used. The nonparametric Mann-Kendall test was applied to calculate the trends of rainfall. Spearman's rho test was used to measure the degree of association of rainfall. Sen's slope estimator was used to predict the magnitude of rainfall trend. Linear regression method was used to detect long term trend of rainfall. The wavelet transform method was used to analyze variability of rainfall time series which was applied for the first time in Bangladesh and Pearson correlation method was used to reveal the relationship between rainfall and ground water level. The aims of this study are to investigate the spatiotemporal variability and trend of rainfall, to assess the temporal variability of rainfall time series and to reveal the relationship between rainfall and ground water level in the northwestern region, Bangladesh.

\section{Materials and methods}

\subsection{Study area}

Bangladesh is a riverine, low-lying and a densely-populated country located in South Asia. Rainfall dominating the climate of Bangladesh including the northwestern region. The present study area for spatiotemporal analysis of rainfall includes six stations of the 
northwestern region, Bangladesh. The stations are Syedpur, Dinajpur, Rangpur, Bogra, Rajshahi and Ishwardi and the study area also shows the ground water level includes five districts of northwestern region, viz, Dinajpur, Rangpur, Bogra, Rajshahi and Pabna. The northwestern part denotes the Rajshahi division and Rangpur division of Bangladesh. The study area is situated between 25000 ' $\mathrm{N}$ to 25050 'N latitudes and 89000 'E longitudes. Figure 1 shows the location map of the study area.

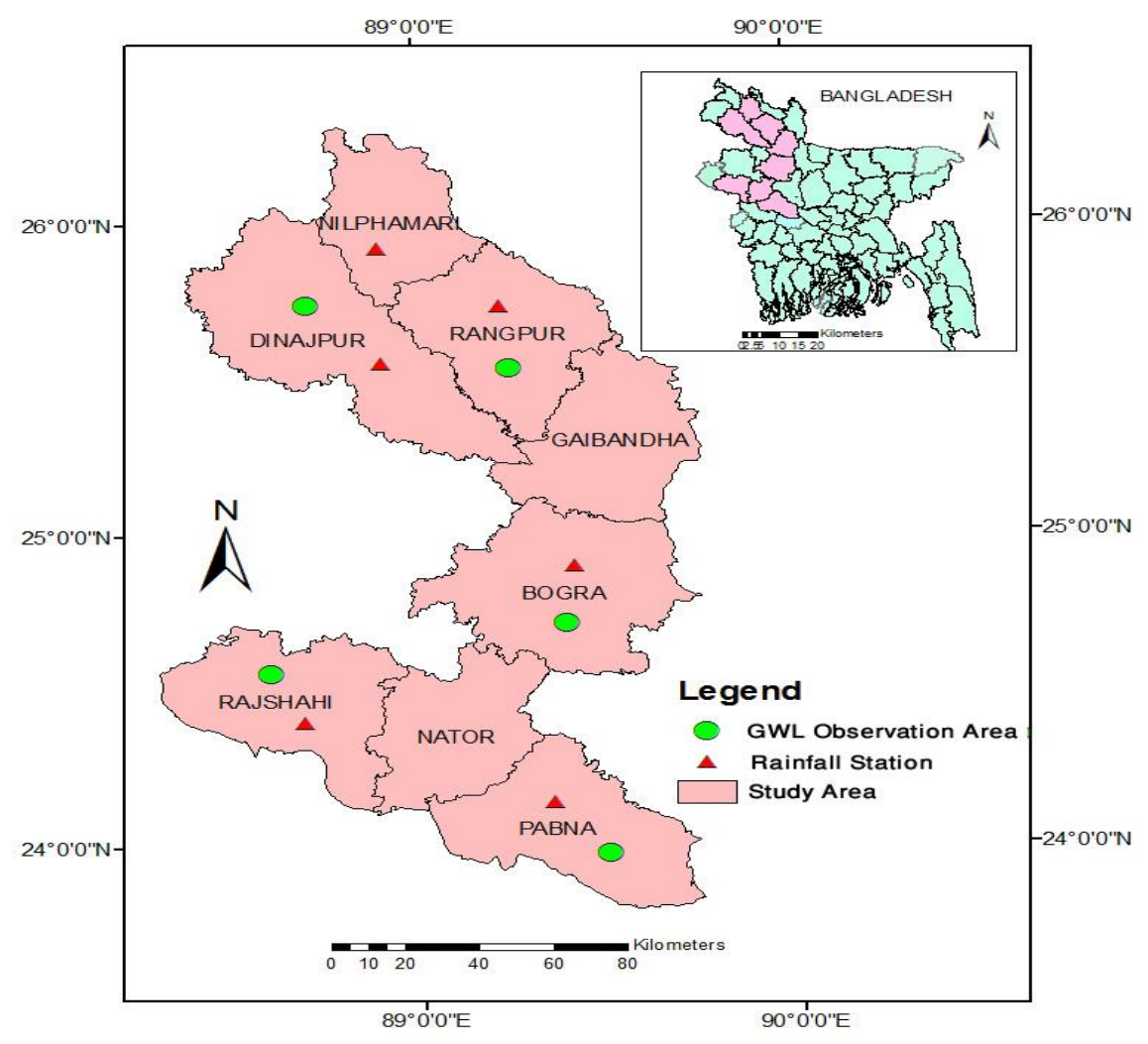

Figure 1: Location map of the study area.

\subsection{Data}

To analyze spatiotemporal variability and trend for the study area, the monthly rainfall data of the 6 stations of the northwestern region during the period of 1976 to 2016 have been collected from the Bangladesh Meteorological Department (BMD), Agargaon, Dhaka. Dinajpur and Syedpur stations have data record for the period of 1981 and 1991. Ground water level data of the 5 districts of northwestern region for the period of 1981 to 2014 have been collected from Bangladesh Water Development Board (BWDB). Locations of rainfall stations and ground water observation districts are shown in Figure 1.

To analysis annual variability and trend of rainfall and its relation with ground water level, first the monthly data were calculated and then accumulating those data to annual data. To analysis seasonal variability and trend of rainfall, first the monthly data were calculated and then accumulating those data according to season. For the pre-monsoon season, data of March, April and May were included. For monsoon season, data of June, July and August were included. For the post-monsoon season, data of September, October and November were included. For the winter season, data of December, January and February were included. Average monthly rainfall data and monthly data of Rangpur and Dinajpur stations were calculated to study wavelet analysis for identification of rainfall variability in this area. Besides annual and seasonal average of rainfall data for the period were calculated to study linear trends. Detailed descriptions of the methods are given below-

\subsection{Statistical analysis}


The basic statistical parameters such as min, max, mean, standard deviation (SD), skewness and kurtosis of rainfall were adopted in the present study for statistical analysis of rainfall. Also coefficient of variation (CV) was applied to detect the variations in rainfall and Pearson correlation was applied to give the relation between rainfall and ground water level.

\subsubsection{Variability analysis (Coefficient of Variation)}

A measure of normalized of the spread about the mean was measured by the coefficient of variation (CV). In this study CV was used to detect the variations in rainfall. It is estimated by the Eq. (1).

$\mathrm{CV}=\frac{s}{x} \times 100$

Where, the $\mathrm{x}$ is the mean and the $\mathrm{S}$ is the standard deviations. Annual and seasonal variability of rainfall in the study area were analyzed using coefficient of variations. CV values $<20 \%$ indicates less variable, between $20 \%$ and $30 \%$ indicates moderately variable and $>30 \%$ indicates highly variable (Teyso et al., 2016).

\subsubsection{Pearson correlation}

In statistics, the Pearson correlation is a measure of the linear correlation between two variables $\mathrm{X}$ and $\mathrm{Y}$. It has a value ranging between +1 and -1 , where 1 is a total positive linear correlation, 0 is no linear correlation, and -1 is a total negative linear correlation. Karl Pearson developed this. In the present study Pearson correlation was used to reveal the relationship between rainfall and ground water level.

Pearson's correlation coefficient when applied to a sample is commonly represented by the letter $r$ and may be referred to as the sample Pearson correlation coefficient. Containing $n$ values then that formula for $r$ is given below Eq. (2).

$$
\mathrm{r}=\frac{\sum_{i=1}^{n}\left(x_{i}-\bar{x}\right)\left(y_{i}-\bar{y}\right)}{\sqrt{\sum_{i=1}^{n}\left(x_{i}-\bar{x}\right)^{2} \sqrt{\sum_{i=1}^{n}\left(y_{\bar{i}}-\bar{y}\right)^{2}}}}
$$

where, $\mathrm{n}$ is the sample size. xi, yi are the single samples indexed with $\mathrm{i}$ and $\bar{x}=\frac{1}{n} \sum_{i=1}^{n} x_{i}$ is the sample mean and analogously for $\bar{y}$
(Kozak 2008).

\subsection{Methods of trend analysis}

Many methods are available to describe spatiotemporal trends of rainfall and ground water level. These methods may be classified into several categories. The methods of

trend analysis is given below.

\subsubsection{Mann-Kendall test}

The non-parametric Mann-Kendall test was applied to calculate the trends of rainfall and ground water level. For detecting a trend in hydro-climatic time series, Mann- Kendall (MK) test is one of the most important statistical methods commonly used in it. In this paper, the MK test was used to detect the trends of rainfall and ground water level. Its statistic is depended on plus or minus signs, that's why the nonparametric Mann-Kendall test is useful (Ye et al., 2017).

The Mann-Kendall statistic $S$ is described by the Eq. (3).

$\mathrm{S}=\sum_{i=1}^{n-1} \sum_{j=i+1}^{n} \operatorname{sign}(x j-x i)$

Where $x \mathrm{j}$ and $x \mathrm{l}$ are the annual values in years $j$ and $\mathrm{i}$, respectively, and $\operatorname{Sign}(d)=1$, if $d>0$; Sign $(d)=0$, if $d=0$; and $\operatorname{Sign}(d)=-1$, if $d<$ 0 . The variance of $S$ can be computed using the following Eq. (4). 
$\operatorname{Var}(S)=\frac{\left[n(n-1)(2 n+5)-\sum_{i=1}^{n} t_{i} i(i-1)(2 i+5)\right]}{18}$

Where $t_{1}$ is the number of ties of extent $i$. For $n>10$, the test is conducted using a normal distribution approximation and the standardized test statistic (Z) is given as following Eq. (5).

$\mathrm{Z}=\frac{S-1}{\sqrt{\operatorname{Var}(S)}}$, if $\mathrm{S}>0$;

$\mathrm{Z}=0$, if $\mathrm{S}=0$;

$\mathrm{Z}=\frac{S+1}{\sqrt{\operatorname{Var}(S)}}$, if $\mathrm{S}<0$.

An upward trend was indicated by a positive $Z$ while a negative Zindicated a downward trend. A statistically significant trend was evaluated using the $Z$ value and here the statistics $Z$ had a normal distribution. For testing either an upward or downward monotone trend (a two-tailed test) Significance level $\alpha$ was used. If $Z$ appears greater than $Z \alpha / 2$ where $\alpha$ depicts the significance level, then the trend is considered as significant. The value for $Z \alpha / 2$ is obtained from the standard normal cumulative distribution tables for the significance levels (a) $0.001,0.01,0.05$ and 0.1 (Ye et al., 2017).

\subsubsection{Spearman's rho}

The degree of association is measured between two variables and to give the correlation between time and the data, Spearman's rho test is used (Meshram et al., 2016). In this study it was used to measure the degree of association of rainfall and to show the correlation. Spearman was developed it and for this it is called as Spearman's rank correlation. It was a non-parametric test which is computed by the Eq. (6).

$\mathrm{R}=1-\frac{6 \sum d^{2}}{n^{3}-n}$

Where, $\mathrm{R}$ denotes the Spearman's rank correlation, $\mathrm{d}$ denotes the difference in the rank, and $\mathrm{n}$ is the total number of the data.

\subsubsection{Sen's slope estimator}

Sen's slope can be estimated by using a nonparametric procedure developed by Sen (1968). The Theil-Sen estimator (Sen 1968; Theil 1950) was used to estimate the slope of $n$ pairs of data points. In this study the Theil-Sen estimator identified the slope of the trend line in rainfall time series. Sen's estimator predicted the magnitude of trend; here the slope $T_{i}$ of all data pairs is computed by the Eq. (7).

$\mathrm{T}_{\mathrm{i}}=\frac{x_{j}-x_{i}}{j=i}$

Where, $x^{j}$ and $x i$ are considered as the data values at time $j$ and $I(j>i)$ correspondingly. The median of these $N$ values of $T_{i}$ is represented as Sen's estimator of slope. Sen's estimator is computed as:

Qmed $=\mathrm{T}(\mathrm{N}+1) / 2$ if $\mathrm{N}$ appears odd;

Qmed $=[\mathrm{TN} / 2+\mathrm{T}(\mathrm{N}+2) / 2] / 2$ if $\mathrm{N}$ appears even

A positive value of Qi indicates an upward or increasing trend, and a negative value of Qi gives a downward or decreasing trend in the time series (Shahid, 2010).

\subsubsection{Linear regression method}

To detect any trends in rainfall time series data a linear regression analysis using the least square method was applied and the confidence level of $95 \%$ was taken as the threshold (Rahman et al., 2015). This method is used for examining the trends in data over time. For trend detection the most ordinarily utilized methodology is a linear model that examining the trends between data and time series in the following Eq. (8).

$\mathrm{x}_{\mathrm{t}}=\alpha+\beta \cdot \mathrm{t}+\varepsilon \mathrm{t}$

Where, $x t(t=1,2, \ldots, n)$ denotes the observed value of time $t, \alpha$ and $\beta$ are the regression coefficients, and $\varepsilon$ denotes the random error 
(white noise) with a zero mean and variance of S2v.

In seasonal and annual rainfall, long-term trends are determined by a linear regression model that was extensively used in this study. An increasing trend is indicated by the positive slope value and a decreasing trend is indicated by the negative value. The aggregated change for the consideration period was gained by multiplying of the slope by the number of years (Meshram et al., 2016).

\subsection{Wavelet transform}

To analyze time series the wavelet transform can be used that contain power which is non-stationary at many several frequencies (Torrence \& Compo, 1998). The Morlet wavelet is demonstrated as a complex explicatory wave product and a Gaussian envelope that is calculated by the Eq. (9).

$\Psi(\eta)=\pi^{-1 / 4} e^{i \omega 0 \eta} e^{-\eta 2 / 2}$

where $\Psi 0(\eta)$ is the wavelet value at non-dimensional time $\eta$, and $\omega 0$ is the non-dimensional frequency, equal to 6 in this study in order to satisfy an admissibility condition; i.e., the function must have zero mean and be localized in both time and frequency space to be "admissible" as a wavelet. This is the function of basic wavelet. The "scaled wavelets" are defined by the Eq. (10).

$\Psi\left[\frac{\left(n^{\prime}-n\right) d t}{s}\right]=\left(\frac{d t}{s}\right)^{1 / 2} \Psi_{0}\left[\frac{\left(n^{\prime}-n\right) d t}{s}\right]$

where the "dilation" parameter is s which is used to change the scale, the translation parameter is n which is used to slide in time. The s$1 / 2$ factor is a normalization which keeps the total energy of the wavelet constant scaled. Each value is separated in time by a constant time interval $\delta$ t. The wavelet transform $W_{n}(s)$ is just the inner product (or convolution) of the wavelet function with the original time series in the following Eq. (11).

$\mathrm{W}_{\mathrm{n}}(\mathrm{s})=\sum_{n^{\prime}=0}^{N-1} x_{n^{\prime}} \Psi^{*}\left[\frac{\left(n^{\prime}-n\right) d t}{s}\right]$

The asterisk $\left(^{*}\right)$ denotes complex conjugate. A new time series of the projection amplitude versus time can be constructed by sliding this wavelet along the time series (Torrence \& Compo, 1998).

\subsection{Spatial distribution analysis}

Spatial analysis is one kind of geographical analysis used to spatial expression and location examination (Rahman et al., 2016). The Inverse Distance Weighting (IDW) method was used to interpolate spatial distribution of rainfall. It is based on the assumption that the weighted average of known values within the neighbourhood is used to estimate the value of a non-sampled point (Lu and Wong, 2008). In the present study the Inverse Distance weighting (IDW) method was used to interpolate variability and trend of rainfall using ArcGIS 10.3 software. IDW is a very flexible spatial interpolation method. It is easy to use to interpolate spatial distribution. Its easiness and estimate accuracy is better than other interpolation methods. For these reasons, IDW method was used in this study to interpolate spatial distribution. MS Excel, SPSS, Past, Mat lab, and R software were used to carry out this study.

\section{Results and discussion}

\subsection{Statistical analysis of rainfall variability}

In this study, the annual rainfall data of 6 meteorological stations have been analyzed to explore the rainfall variability in the northwestern region. Basic statistical parameters such as min, max, mean, standard deviation (SD), skewness and kurtosis of rainfall for the 6 stations are displayed in Table 1. The central tendency and dispersion were determined by the statistical analysis of data. The variability in annual rainfall was denoted by the high standard deviation and it showed that how rainfall is dependable in terms of its existence. Table 1 shows the high variation at each meteorological station in minimum and maximum annual rainfall. Mean annual rainfall was the highest in Rangpur which indicates the highest annual rainfall received at this station and the mean annual rainfall was the lowest in Rajshahi which indicates the lowest annual rainfall received at this station. Mean annual rainfall of different stations varied from 1472.73 to $2365.87 \mathrm{~mm}$. The highest standard deviation was found in Rangpur ( $583.56 \mathrm{~mm}$ ) followed by Syedpur ( $502.71 \mathrm{~mm})$, which showed that in annually there is high variability in the amount of rainfall received. The skewness and kurtosis were analyzed to check the distribution normality of annual rainfall data. The skewness denotes the symmetry of the data. For normal data distribution the skewness is zero and any symmetric data should have near zero skewness. All the meteorological stations showed positive skewness, which indicates that the 
amount of rainfall distribution was normal. Data flatness relative to a normal distribution is measured by kurtosis. The high kurtosis tends to have high peak near the mean and dataset with low kurtosis have a flat peak near the mean. Normal distribution of data has the zero kurtosis. The positive kurtosis indicates the peaked distribution. The Ishwardi and Rangpur stations had high kurtosis. The present study shows positive skewness in all the stations. Rahman et al., (2018) analyzed on spatial rainfall variability and drought assessment in the Khyber Pakhtunkhwa province of Pakistan by calculating various indices like standard deviation, skewness, and kurtosis from annual rainfall of 15 meteorological stations during periods of 1971-2015. Their findings showed that all the stations showed a positive skewness except one. These results are consistent with the present study. According to Khan (2015), the areas where annual mean rainfall exceeds $750 \mathrm{~mm}$ are classified as humid areas. In this study, all the stations exceed $750 \mathrm{~mm}$ in annual mean rainfall which indicates humid areas.

Table 1 Statistical parameters of annual rainfall at 6 meteorological stations of the North-Western region (1976-2016).

\begin{tabular}{ccccccc}
\hline Stations & $\begin{array}{c}\text { Min rainfall } \\
(\mathrm{mm})\end{array}$ & $\begin{array}{c}\text { Max rainfall } \\
(\mathrm{mm})\end{array}$ & $\begin{array}{c}\text { Mean rainfall } \\
(\mathrm{mm})\end{array}$ & $\begin{array}{c}\text { Standard } \\
\text { Deviation }(\mathrm{mm})\end{array}$ & Skewness & Kurtosis \\
\hline Rangpur & 1301 & 3975 & 2365.87 & 583.56 & 1.176 & 0.415 \\
Dinajpur & 1142 & 3116 & 1982.72 & 443.78 & 0.463 & -0.231 \\
Syedpur & 1244 & 3145 & 2100.62 & 502.71 & 0.692 & -0.731 \\
Bogra & 1081 & 2601 & 1744.19 & 389.18 & 0.146 & 0.111 \\
Rajshahi & 792 & 2241 & 1472.73 & 304.86 & & 0.344 \\
Ishwardi & 894 & 2845 & 1553.36 & 394.33 & & \\
\end{tabular}

\subsubsection{Analysis of annual and seasonal rainfall variability}

Rainfall variability is the fluctuations of rainfall above or below a long term normal value occurring annually or seasonally. The northwestern region of Bangladesh is more vulnerable to climate change due to high special and temporal rainfall variability. The variability of rainfall varies from location to location. For assessment of crop water requirements, seasonal rainfall variability is more important (Hossain et al., 2010).

Figure 2 shows the annual rainfall variability and Figures 3 shows the seasonal (pre-monsoon, monsoon, post-monsoon and winter) rainfall variability of the northwestern region. From the Figure 2, it shows that the annual rainfall variability was the highest in the Ishwardi station $(25.39 \%)$. The lowest annual rainfall variability was found in Rajshahi $(20.70 \%)$. The range of annual rainfall variability was 20.70 - $25.39 \%$ per year. Spatial variation showed that the highest annual rainfall variability ranges between $24.67-25.39 \%$ per year in the northwestern region. Figure 3 shows that in the pre-monsoon season the highest rainfall variability was $50.17 \%$ found in Ishwardi. The lowest rainfall variability in the pre-monsoon season was $32 \%$ found in Rangpur. The range of pre-monsoon rainfall variability was 32 $50.17 \%$. For the pre-monsoon season the highest rainfall variability ranges between $48.85-50.17 \%$. During the monsoon season the highest rainfall variability was $37.10 \%$ found in Ishwardi. The lowest rainfall variability in the monsoon season was $20.70 \%$ found in Rajshahi. The range of monsoon rainfall variability was $37.10-20.70 \%$. For the monsoon season the highest rainfall variability ranges between $32.99-37.10 \%$. During the post-monsoon season the highest rainfall variability was $45.26 \%$ found in Dinajpur. The lowest rainfall variability in the post-monsoon season was $36.67 \%$ found in Ishwardi. The range of post-monsoon rainfall variability was $36.67-45.26 \%$. For the post-monsoon season the highest rainfall variability ranges between $41.80-45.26 \%$. During the winter season the highest rainfall variability was $93.97 \%$ found in Bogra. The lowest rainfall variability in the winter season was $77.94 \%$ found in Rangpur. The range of winter rainfall variability was $77.94-93.97 \%$. For the winter season the highest rainfall variability ranges between $89-93.97 \%$. In the present study it is found that the northwestern region had experienced the highest rainfall variability in the winter season than the other seasons. It was between $89-93.97 \%$ per year. The annual rainfall variability was lower than the seasonal rainfall variability in the northwestern region. In the present study, variation analysis showed that rainfall in this region was erratic during the pre-monsoon season (50.17\% per year) and become more erratic during the winter season (93.97\% per year) for the last 40 years. In these season variability occurred due to low precipitation which received in the pre-monsoon and winter season. For this those seasons had more rainfall variability than other seasons. 
Rahman and Lateh (2015) analyzed the spatiotemporal variation in rainfall and temperature trends over Bangladesh for 40 years (1971-2010) by using MK test, CV. In their study, they analyzed 34 stations and observed that the annual rainfall variability was highest in the northwestern and northern part of Bangladesh. The pre-monsoon rainfall variability was also remarkable for this region. They mentioned that there was decreasing in rainfall in the northwestern region and also for Bangladesh than the past. Their analysis is consistent with the present study.

The northwestern region experienced declines in rainfall in the recent decades. For this high rainfall variability occurs in this area. In Bangladesh the decreasing of rainfall occurs during El-Nino years. This is the main cause of high rainfall variability (Ahmed et al., 1996). A study by Rajeevan et al., (2008) found that the inter-decadal and annual variability of rainfall may be linked with the variations and anomalies of sea surface temperatures over the Equatorial Indian Ocean and also for the sea surface temperature over the Equatorial Indian Ocean and also for the global warming. For this the variations in the rainfall can occur. For these variations in rainfall the northwestern region in Bangladesh is the most vulnerable to drought.

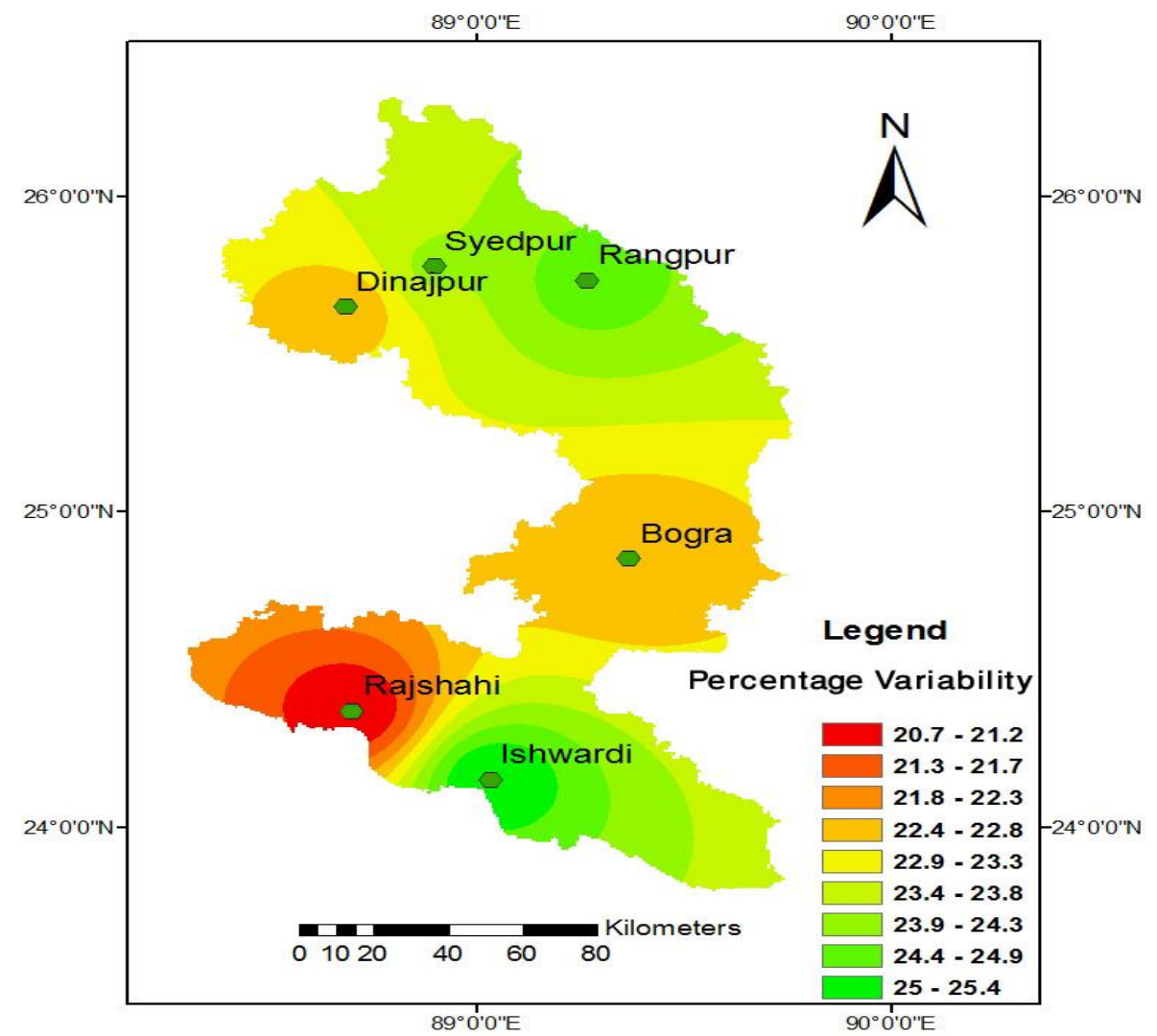

Figure 2: Spatial variability $(C V)$ of annual rainfall in the study area. 
(a) Pre-monsoon
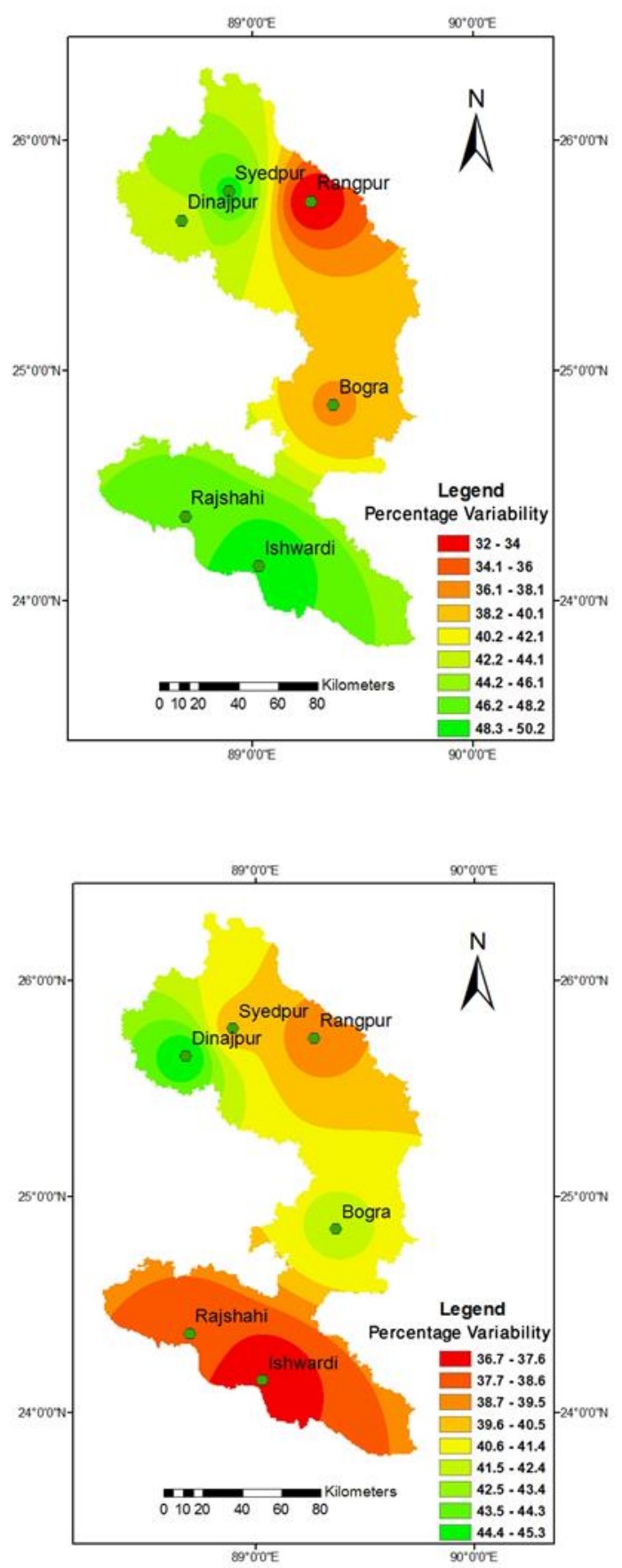

(b) Monsoon
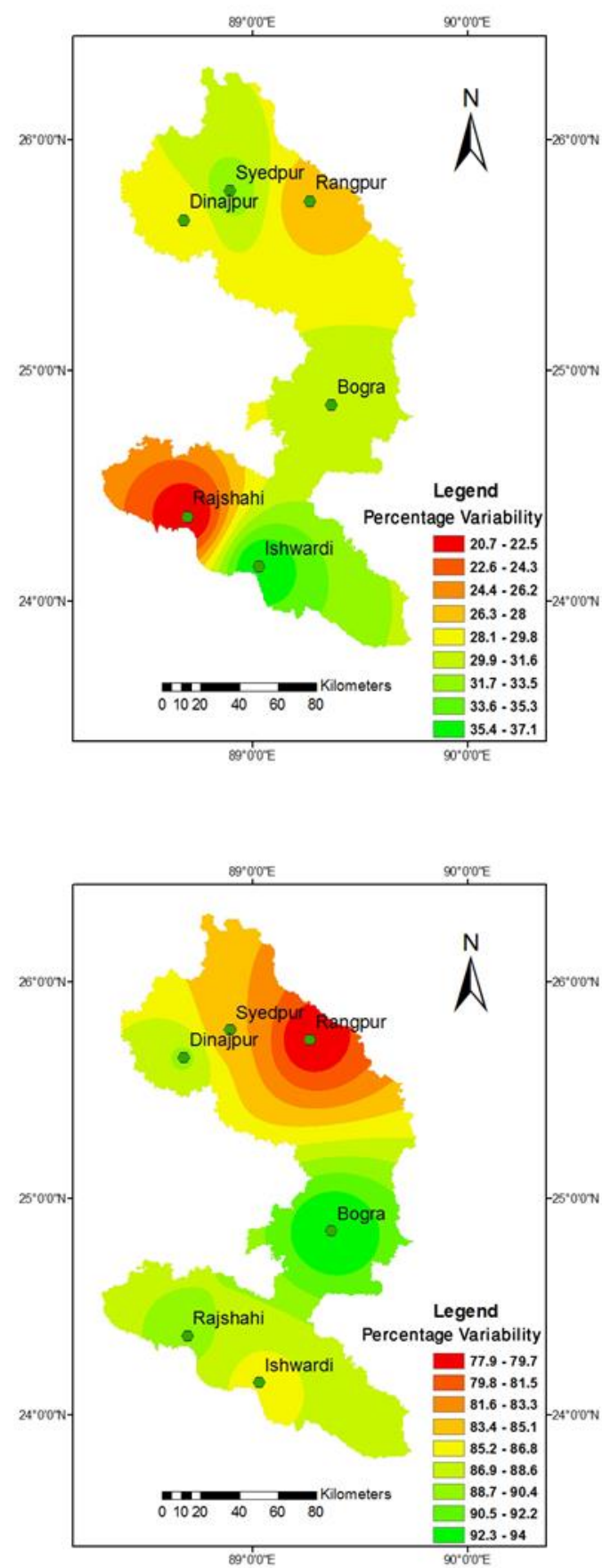
Figure 3: Spatial variability (CV) of seasonal rainfall in the study area.

\subsection{Spatio-temporal trend analysis of rainfall}

Rainfall of Bangladesh varies, depends on season and location. Rainfall in the study area is erratic and low with an average value of $1483 \mathrm{~mm}$ per year. Here most of the rainfall occurs between June and September. Spatiotemporal variation of rainfall in this area is very common (Choudhury et al.,2003). The results of this study on the spatiotemporal trend analysis of rainfall over the northwestern part of Bangladesh for the period of 1976-2016 have been analyzed and discussed here. Mann-Kendall test, Sen's slope estimator, Spearman's rho test, linear regression model is used for spatiotemporal trend analysis of this study.

\subsubsection{Spatial trend analysis of annual and seasonal rainfall}

Figure 4 shows the $Z$ values of the MK test of annual rainfall and Figure 5 shows the $Z$ values of the MK test for the seasonal (premonsoon, monsoon, post-monsoon and winter) time scales of 6 selected stations. These methods are used to reveal the trends of rainfall in the northwestern region, Bangladesh. Rainfall trends for the period of 41 years (1976-2016) are analyzed.

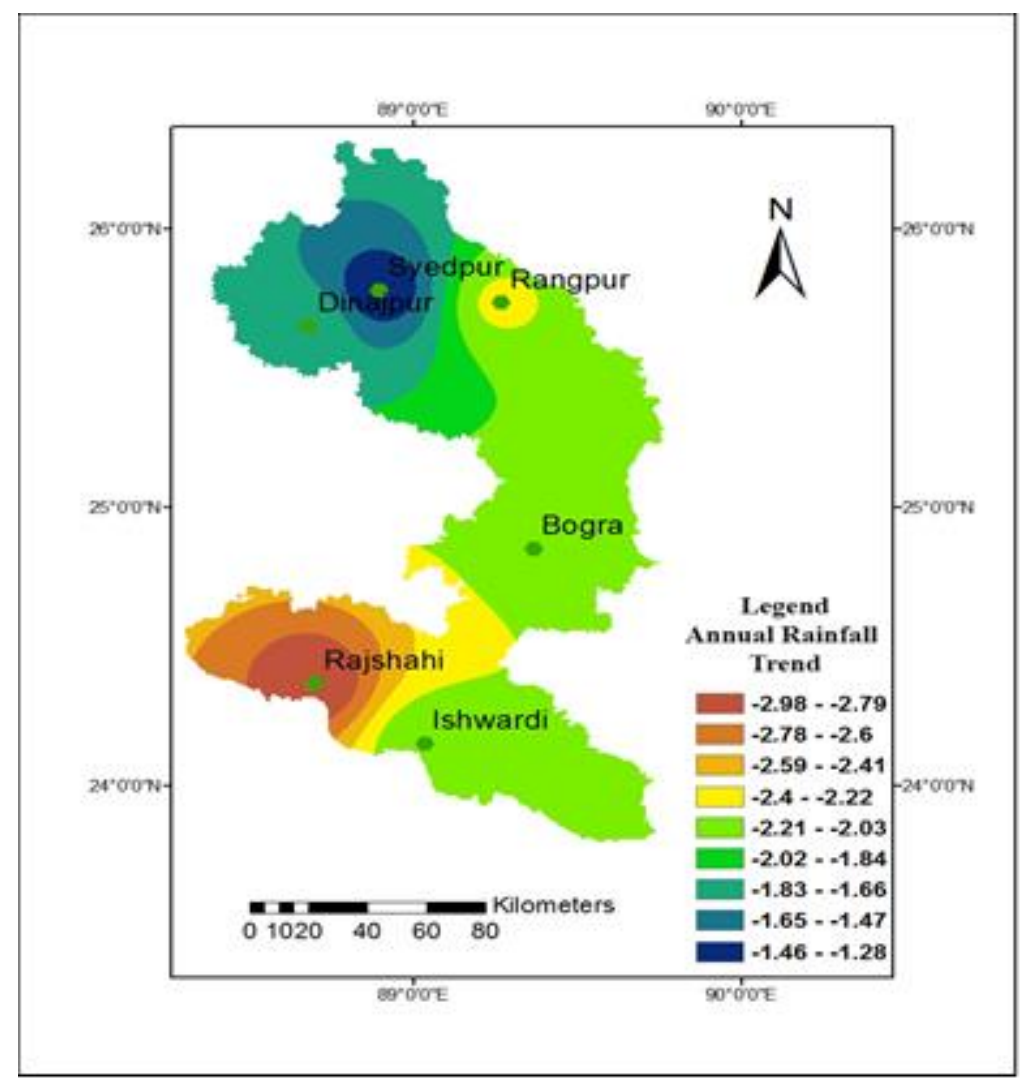

Figure 4: Spatial distribution of MK Z values for the annual rainfall trend during 1976-2016.

For the annual rainfall it is found that (from Fig.4) the number of decreasing trends using the MK test at significant $95 \%$ and $99 \%$ lev els were found to be 3 and 1 respectively. The positive $Z$ value indicates increasing trend and the negative value indicates a decreasin $g$ trend. Two stations showed decreasing insignificant trends in the annual rainfall. Out of 6 stations no station showed an increasing tren $\mathrm{d}$ in the annual rainfall. From the Figure 4 it is shown that the highest decreasing trend of annual rainfall was found in the Rajshahi statio $\mathrm{n}$ that was $-2.976 \mathrm{~mm}$ per year, which was significant and the lowest decreasing trend of annual rainfall was found in the Syedpur station that was $-1.278 \mathrm{~mm}$ per year which was insignificant. It is found that for the Sen's slope of annual rainfall, the most decreasing trend wa 
$\mathrm{s}$ found in Syedpur that was $-17.33 \mathrm{~mm}$ per year and the less decreasing trend was found in Ishwardi that was $-10.44 \mathrm{~mm}$ per year. In th is case the Sen's slope result and MK test value do not comply with each other. For annual rainfall the magnitude of negative trend was $i$ $\mathrm{n}$ the range of 10.44 to $17.33 \mathrm{~mm}$ per year. No positive or increasing trend was found in annual rainfall. From one station to another rainf all trend showed variability in the magnitude. The Spearman's rho test and MK test value fully comply with each other.

(a) Pre-monsoon
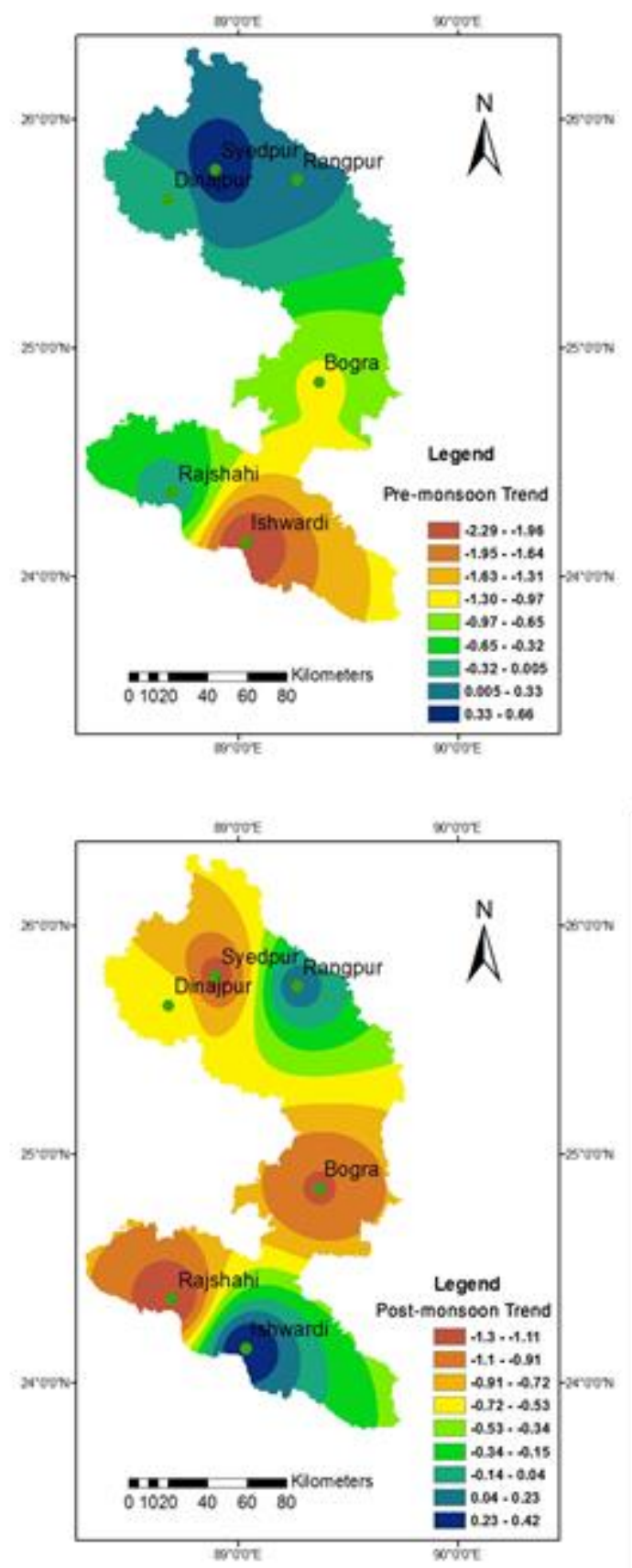

(b) Monsoon
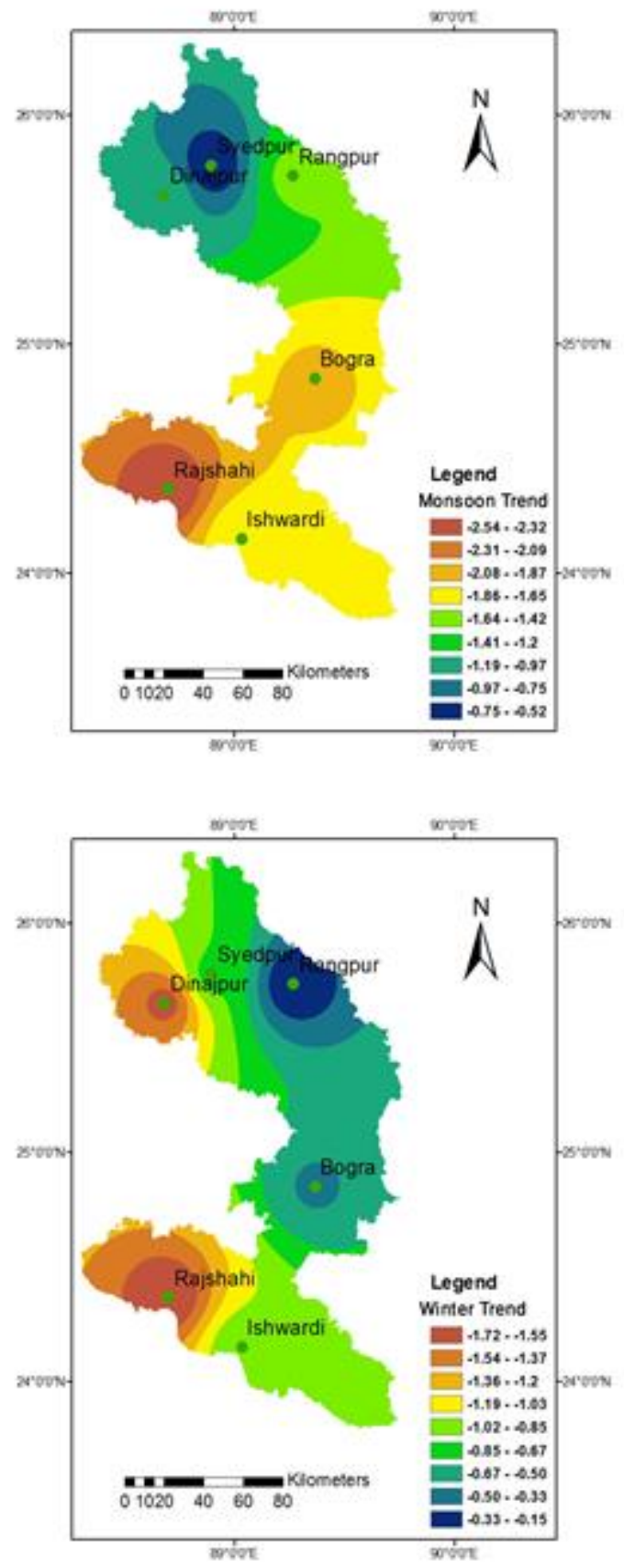

Figure 5: Spatial distribution of MK Z values for the seasonal rainfall trend during 1976-2016.

In the pre-monsoon season, two stations showed positive or increasing trends in rainfall. These two stations were Rangpur and 
Syedpur. Other stations showed decreasing trends in the rainfall in pre-monsoon season. The highest decreasing trend in the premonsoon season rainfall was found in the Ishwardi station that was $-2.292 \mathrm{~mm}$ per year which was significant. In the monsoon season the number of decreasing trends using the MK test was found to be 6 out of 6 stations. The result showed that all the stations had a decreasing trend in monsoon season rainfall. In those stations 2 stations showed significant decreasing trends in monsoon rainfall. The highest decreasing trend in the monsoon season rainfall was found in the Rajshahi station that was -2.538 mm year which was significant.

In the post-monsoon season the number of decreasing trends was found at 4 stations. 2 stations had a positive or increasing trend in rainfall in the post-monsoon season. The highest decreasing trend in the post-monsoon season rainfall was found in the Rajshahi station that was $-1.303 \mathrm{~mm}$ year which was insignificant. In post-monsoon season there was no significant increasing or decreasing trend was found. The result showed that in the winter season all the selected stations had the decreasing trends in rainfall. There was no significant decreasing trend in rainfall was found in the winter season. The highest decreasing trend in the winter season rainfall was found in the Rajshahi station that was $-1.721 \mathrm{~mm}$ year which was insignificant. The Mann-Kendall test identified an increasing trend in pre-monsoon rainfall for Rangpur and Syedpur, also an increasing trend for Rangpur and Ishwardi in post-monsoon season. Monsoon and winter season represent decreasing trends of rainfall for all stations. That means the northwestern regions received less rainfall in the monsoon and winter season than the past.

From supplementary (Table S2), in pre-monsoon season only two stations showed the positive values of Sen's slope estimator for Rangpur and Syedpur. Four other stations had declining trends in the pre-monsoon season. In the monsoon season all stations had declining trends. In post-monsoon season only two stations showed the positive values of Sen's slope estimator for Rangpur and Ishwardi. Four other stations had declining trends. All stations had declining trends in the winter season except one station that was Rangpur. The Sen's slope result and MK test value comply with each other except one for Rangpur in winter season. Spearman's rho showed the same results as the Sen's slope except winter season. All the stations showed negative trend in the winter season in the Spearman's rho test and in Sen's slope 5 out of 6 stations showed negative trends in this season.

In the present study the three tests (MK test results, Spearmon's rho and Sens's slope) values are complying with each other in case of positive and negative value in all the stations for annual and seasonal rainfall except for the one station in winter season. The MK test result and Spearman's rho in winter season for Rangpur station is negative but in Sen's slope there is a positive value in Rangpur station for winter season.

Annual rainfall in the northwestern region, Bangladesh showed negative trends. Which means the annual rainfall in this area was decreasing. In the present study the northwestern climatic region of Bangladesh experienced a negative trend. Rangpur, Bogra and Rajshahi districts had a significant negative trend in annual rainfall that means these stations received low annual precipitation than the past. Rahman et al., (2016) analyzed the rainfall trend over Bangladesh for the 60 years (1954-2013) and applied the MK test, and Sen's slope estimator to detect annual trends for 34 stations. In the result, it was shown that the southeastern and the southwestern part of Bangladesh were experiencing an increasing rainfall trend where a decreasing trend was found in the northwestern region. This finding is consistent with the present study.

The present study correlates with the trends in rainfall over South Asia, which was analyzed by Solomon et al., (2007). In their analysis, it was found that the rainfall significantly decreased in South Asia. Due to climate change the South Asia's rainfall was decreasing and for this many areas becoming arid. Rahman and Lateh (2015) analyzed the spatiotemporal variation in rainfall and temperature trends over Bangladesh for 40 years (1971-2010) by using the MK test. In their study, they analyzed 34 stations and observed that the general trend was positive for the annual rainfall in some regions and negative for seasonal rainfall in the country. Their analysis showed that the greatest rainfall decreased over the year in the post-monsoon season and the rate of rainfall change decelerated in the last 30 years. This analysis agrees with the present study. Shahid (2010) analyzed rainfall variability and trends over Bangladesh using Sen's slope and Spearman's rho. In this analysis, it was found that in the northwestern region Rangpur station was represented an increasing trend in rainfall. It is agreed with the present study except for the annual and monsoon season rainfall. Winter rainfall showed no significant trend in the northwestern region, Bangladesh. This finding is consistent with the other studies (Agrawala et al., 2003; Shahid 2010). Postmonsoon rainfall trend increased non-significantly in the present study that also analogous to other studies (Agrawala et al., 2003; Shahid 2010). Monsoon rainfall in the northwestern region was decreased and this analysis is similar to the other studies (Ahasan et al., 2010; Choudhury et al., 2012).

3.2.2 Temporal trend analysis of annual and seasonal rainfall

Figure 6(a) shows the mean annual rainfall trend and Figure 6(b), 6(c), 6(d) and 6(e) show the mean seasonal (pre-monsoon, 
monsoon, post-monsoon and winter) rainfall trends of the northwestern region during the 41 years (1976-2016). All tests were considered at the $95 \%$ significance level.

(a) Annual

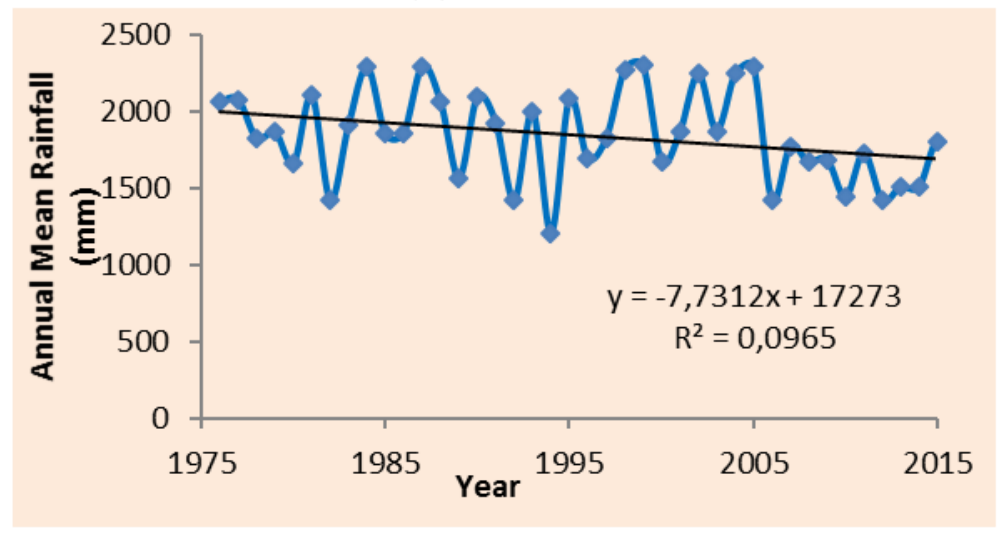

(a) Pre-monsoon
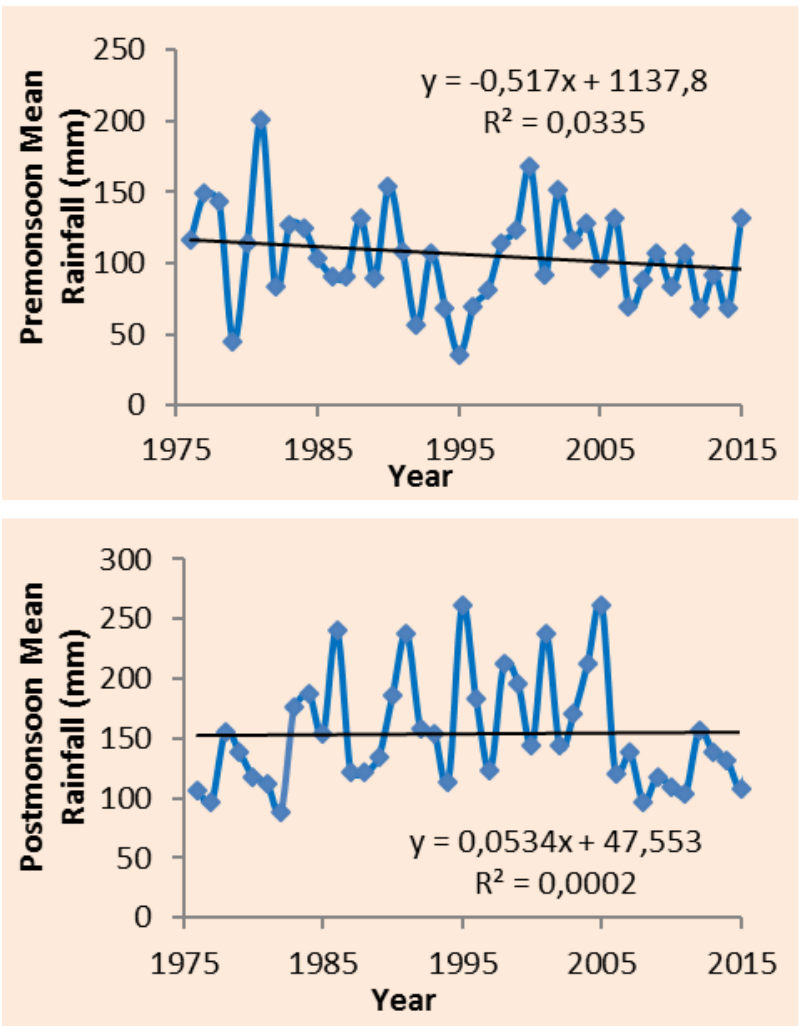

(b) Monsoon
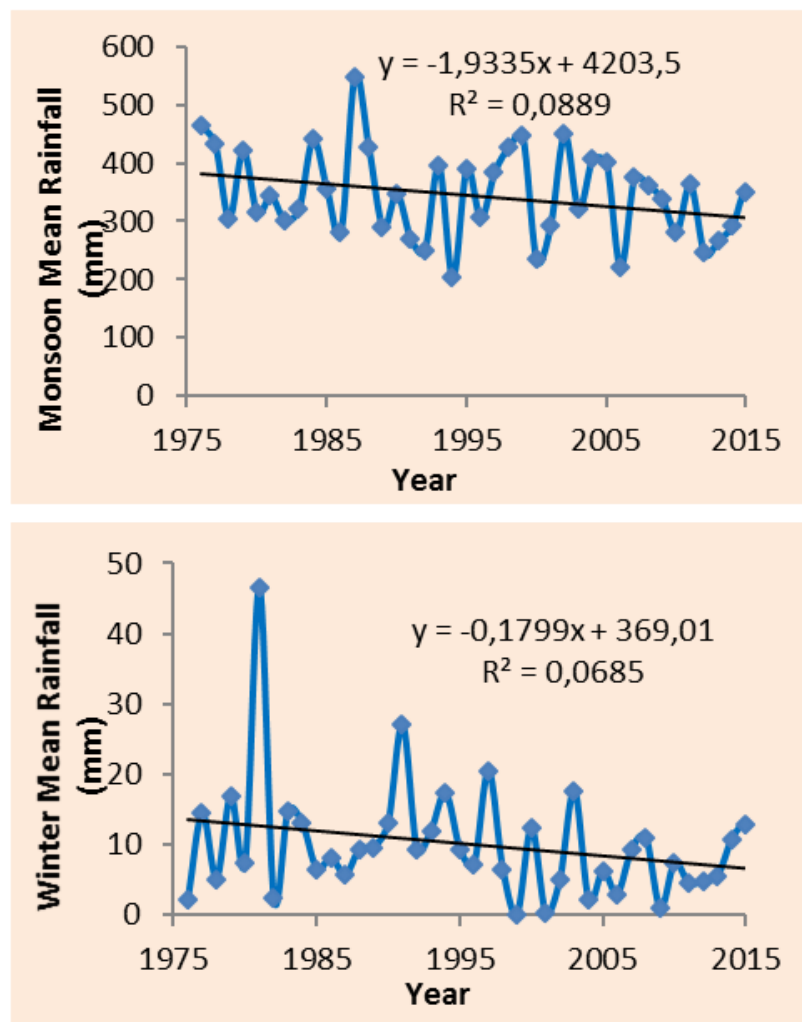

Figure 6: Mean annual and seasonal rainfall distribution in the north.

In this study a decreasing trend was observed for annual rainfall. In Figure 6(a) slope of $-7.73 \mathrm{~mm}$ per year is seen for the annual rainfall. It is observed that there was a decreasing trend in annual rainfall over the northwestern region, Bangladesh. In the present study a decreasing trend was found for the monsoon season rainfall. In the study, pre-monsoon and winter season rainfall had also a decreasing 
trend. But post-monsoon rainfall was showing a little increasing trend. Figures $6(\mathrm{~b}), 6(\mathrm{c}), 6(\mathrm{~d})$ and $6(\mathrm{e})$ represent a slope of $-0.51 \mathrm{~mm}$ per year for pre-monsoon, $-1.93 \mathrm{~mm}$ per year for monsoon, $0.05 \mathrm{~mm}$ per year for post-monsoon and -0.17 mm per year for winter rainfall series. From supplementary (Table S3) the t test statistic indicated that the monsoon and the winter rainfall trend in the northwestern region was significant at the $5 \%$ level.

Rahman and Kamal (2016) analyzed rainfall variability and linear trend models on northwestern part, Bangladesh. They analyzed data of the 40 years (1975-204) over the northwestern part of Bangladesh using a linear trend model. Their linear trend line showed the declining trend in annual rainfall, the decrease of monsoon rainfall trend over northwestern region. In their study the rainfall trend and variability in all stations were decreasing. This analysis agrees with the present study. Ye and Li (2017) analyzed 30 stations on Huaihe river basin, China. They analyzed that there was an increasing trend in annual and winter rainfall. Rainfall intensity was increasing that is disagreed with this study. The IPCC $4^{\text {th }}$ assessment report also mentioned the declining rainfall trend over Bangladesh (IPCC 2007). For the effects of climate change the annual and seasonal rainfall trends are decreasing.

\subsection{Wavelet analysis of rainfall time series}

Rainfall time series can be analyzed by wavelet transform which contain non-stationary power at many different frequencies. Wavelet transform allows analyzing different scales of temporal variability. It does not need a stationary series. To analyze irregular distributed events and time series it is appropriate that contain non-stationary power at many different frequencies. For analyzing localized variations of power within a time series, it is becoming a common tool. Wavelet analysis is done with long time series on the average monthly rainfall of the northwestern region and monthly mean rainfall of Rangpur and Dinajpur station. It is done to analyze the rainfall variability in these areas. The wavelet of rainfall time series is analyzed and discussed here.

\subsubsection{Wavelet power spectrum}

Since the present data are distributed monthly, the wavelet analysis parameters are set as $\delta t=1$ month and $s 0=2$ months because $s=2 \delta t, \delta j=0.25$ to do 4 sub-octaves per octave, and $j 1=7 / \delta j$ in order to do 7 powers-of-two with $\delta j$ sub-octaves each. The figure below (Fig.7.b) shows that the power (absolute value squared) of the wavelet transform for the monthly average rainfall in the northwestern region of Bangladesh. Average monthly rainfall time series is presented in Fig. 7(a).

It has been stated before that the (absolute value $)^{2}$ gives information on the relative power at a certain scale in a certain time. The actual oscillations of the individual wavelets, rather than just their magnitudes are shown in this figure. By observing Fig. 7(b), it shows that there is more concentration of power between the 8-14-months band. In which it is clear that this time series has a strong annual signal. Here it shows that no significant peaks were attained for low frequency periods. However, wavelet power spectrum for rainfall episodes with characteristic scale of 8-14 months (Fig. 7.d) presents five low peaks, at the $5 \%$ significance level.

The Fig. 8(b) shows that the power (absolute value squared) of the wavelet transform for the monthly rainfall in the Rangpur station of Bangladesh. Monthly rainfall time series of Rangpur station is presented in Fig. 8(a). The (absolute value) $)^{2}$ gives information on the relative power at a certain scale in a certain time. By observing Fig. 8(b), it shows that there is more concentration of power between the 8-14-months band. In which it is clear that this time series has a strong annual signal. Here it shows that for this area there is an important significant peak was attained in low frequency periods. Wavelet power spectrum for rainfall episodes with characteristic scale of 8-14 months (fig. 8.d) presents two low peaks, at the $5 \%$ significance level.

The Fig. 9(b) shows that the power (absolute value squared) of the wavelet transform for the monthly rainfall in the Dinajpur station of Bangladesh. Monthly rainfall time series of Dinajpur station is presented in Fig. 9 (a). The (absolute value) ${ }^{2}$ gives information on the relative power at a certain scale in a certain time. By observing Fig. $9(\mathrm{~b})$, it shows that there is more concentration of power between the 8-14-months band, in which it is clear that this time series has a strong annual signal. Here it shows that for this area there is a low significant peak was attained in low frequency periods. Wavelet power spectrum for rainfall episodes with characteristic scale of 8-14 months (Fig. 9.d) presents an important peak and a low peak, at the $5 \%$ significance level.

In these figures, there exists a zone called the cone of influence at the border of the wavelet power spectra, where the variance has reduced by zero padding. In it we are dealing with finite-length time series. In which errors will occur at the beginning and end of the wavelet power spectrum.

Santos et al., (2001) analyzed wavelet transform with the total monthly rainfall data of Matsuyama city, Japan. They analyzed that no significant peaks were attained for low frequency periods. Their results agree with the results of the present study in average monthly 
rainfall and disagree with the results of monthly rainfall of Rangpur and Dinajpur stations of this study.

(a) Average Rainfall Time Series (Monthly mean)

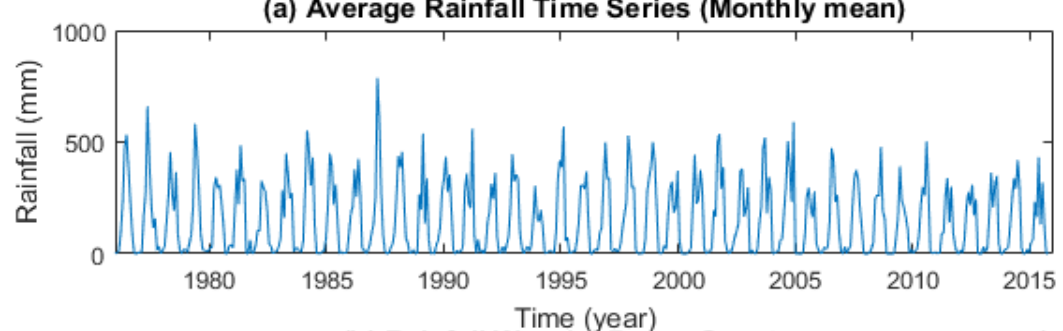

(b) Rainfall Wavelet Power Spectrum

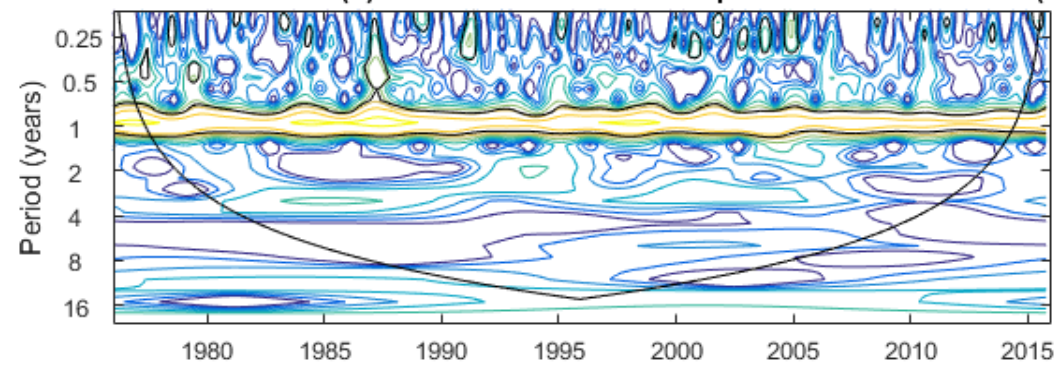

(c) Global Wavelet Spectrum
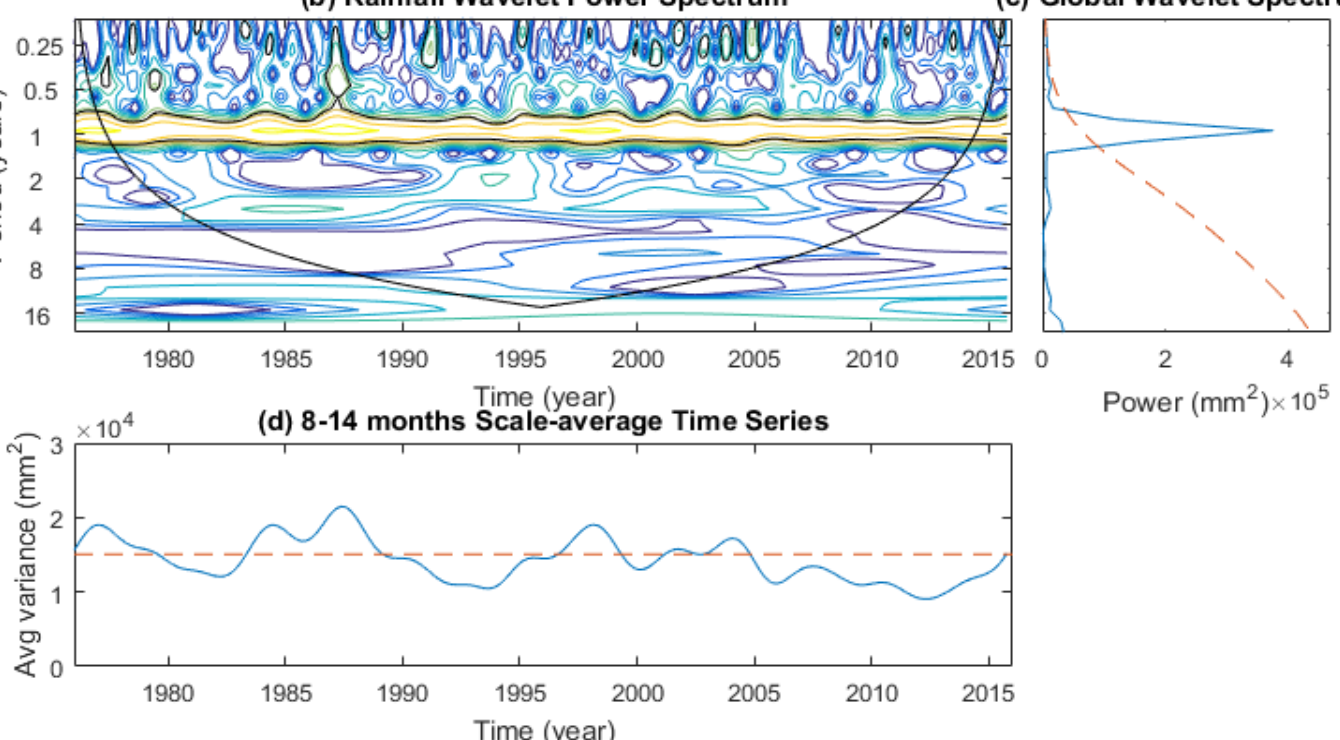

Figure 7: (a) Average monthly rainfall in the northwestern region for 1976-2016 periods. (b) The wavelet power spectrum using Morlet mother wavelet. Crosshatched region is the cone of influence, where zero padding has reduced the variance. Black contour is the $5 \%$ significance level using a red-noise $(\alpha=0.72)$ background spectrum. (c) The global wavelet power spectrum. The dashed line is the $5 \%$ significance level for the global wavelet spectrum; and (d) Scaleaverage wavelet power over the 8-14 months band. The dashed line is the $95 \%$ confidence level assuming red noise $\alpha=0.72$. 
(a) Rainfall Time Series of Rangpur Station (Monthly mean)

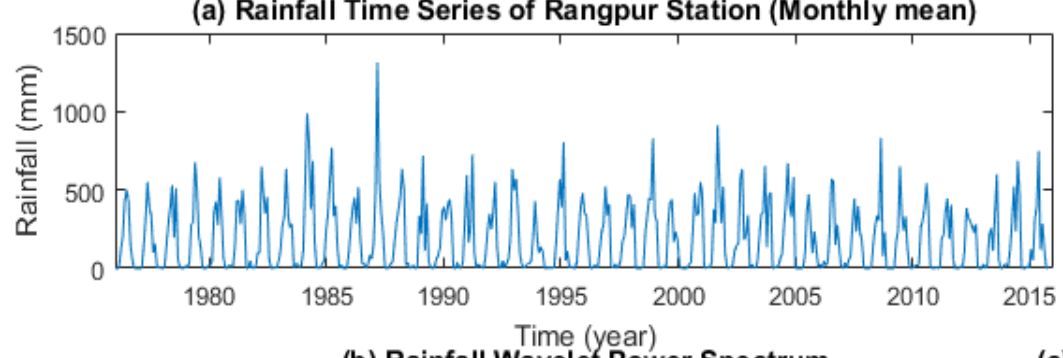

(b) Rainfall Wavelet Power Spectrum

(c) Global Wavelet Spectrum
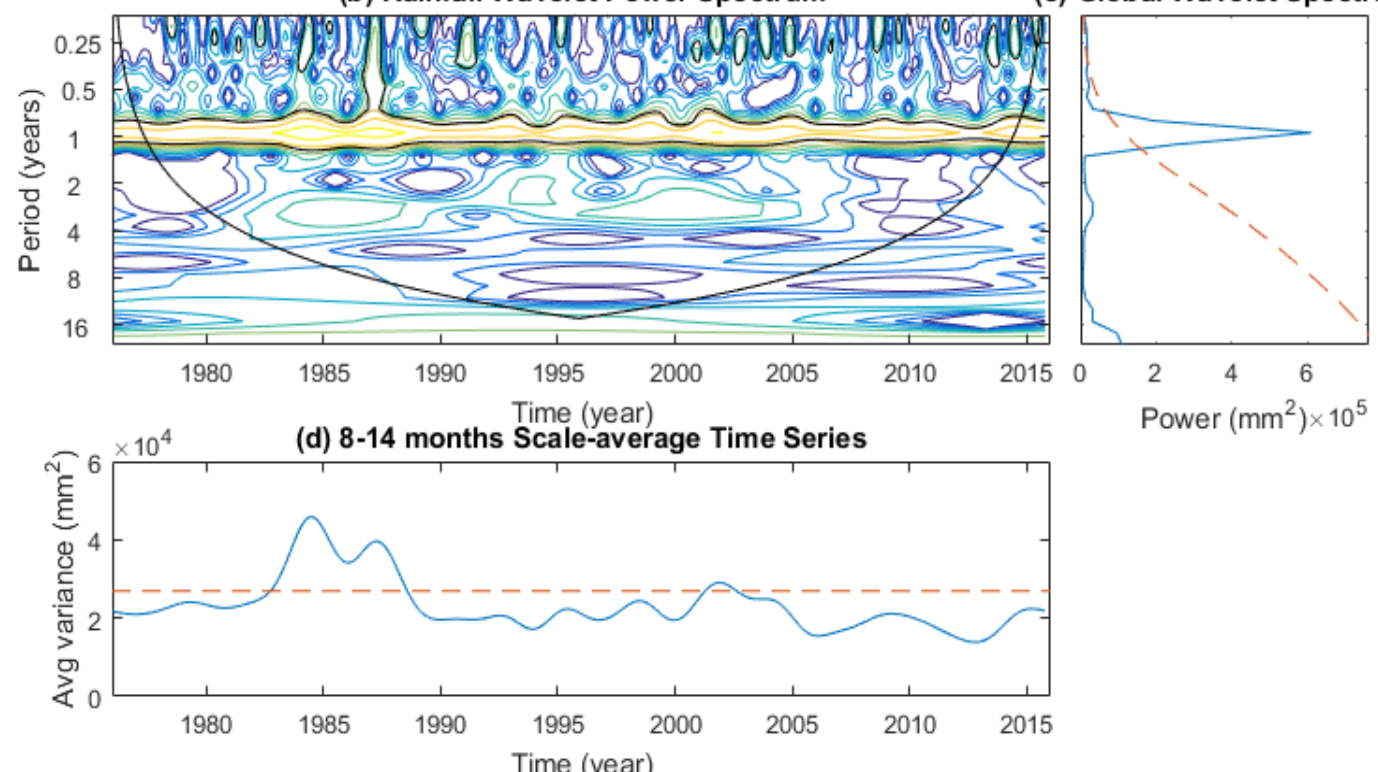

Figure 8: (a) Monthly rainfall in Rangpur station for 1976-2016 periods. (b) The wavelet power spectrum using Morlet mother wavelet. Cross-hatched region is the cone of influence, where zero padding has reduced the variance. Black contour is the $5 \%$ significance level using a red-noise $(\alpha=0.72)$ background spectrum. (c) The global wavelet power spectrum. The dashed line is the $5 \%$ significance level for the global wavelet spectrum; and (d) Scale-average wavelet power over the 8-14 months band. The dashed line is the $95 \%$ confidence level assuming red noise $\alpha=0.72$. 
(a) Rainfall Time Series of Dinajpur Station (Monthly mean)

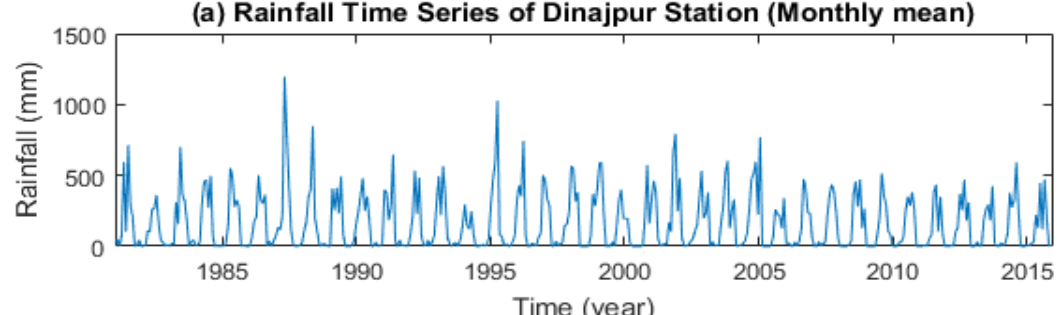

(b) Rainfall Wavelet Power Spectrum

(c) Global Wavelet Spectrum
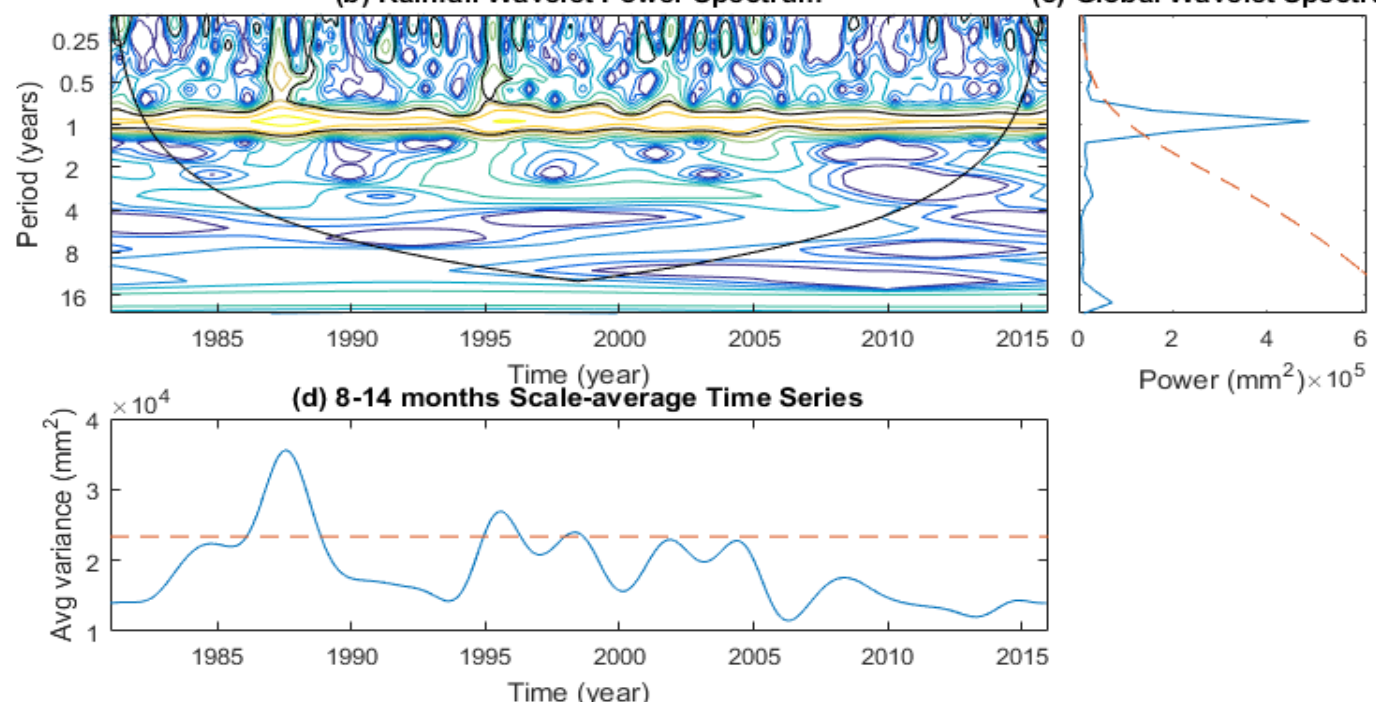

Figure 9: (a) Monthly rainfall in Dinajpur station for 1981-2016 periods. (b) The wavelet power spectrum using Morlet mother wavelet. Cross-hatched region is the cone of influence, where zero padding has reduced the variance. Black contour is the $5 \%$ significance level using a red-noise $(\alpha=0.72)$ background spectrum. (c) The global wavelet power spectrum. The dashed line is the $5 \%$ significance level for the global wavelet spectrum; and (d) Scale-average wavelet power over the 8-14 months band. The dashed line is the $95 \%$ confidence level assuming red noise $\alpha=0.72$.

\subsubsection{Global wavelet power spectrum}

In these time series the annual frequency (12 months) is confirmed by an integration of power over time (Figs 7.c, 8.c and 9.c), in which it shows that only one significant peak above the $95 \%$ confidence level for the global wavelet spectrum, assuming $\alpha=0.72$ represented by the dashed lines. Figures 7(c), 8(c) and 9(c) also present an almost significant peak (at the $5 \%$ level) which centered in the 2-4-months band. Most extreme monthly precipitation values for Rangpur station (values above $1000 \mathrm{~mm}$ in Fig. 8.a) correspond to pulses of highly significant power within the 8-14-months band (Fig. 8.b). This global wavelet power spectrum provides an impartial and balanced estimation of the true power spectrum of the time series. It is a simple and robust method to characterize the time series variability. It is good to use global wavelet spectra to describe rainfall variability in non-stationary hyetographs. In hyetograph structures the regions that do not display long-term changes, global wavelet spectra can be useful for summarizing the region's temporal variability and also compare it with rainfall in other regions. The shape of the global wavelet spectrum is controlled primarily by the distribution of feature scales.

Ideiao and Santos (2005) analyzed precipitation time series of north-eastern Brazil using wavelet. They analyzed that only one significant peak above the $95 \%$ confidence level in the global wavelet spectrum represented by the dashed lines. An almost significant peak centered in the 2-4 months band. Their analysis agrees with this analysis.

\subsubsection{Scale-average time series}

The average variance in a certain band is shown in the scale-average time series (Figs 7.d, 8.d and 9.d). The 8-14-months band is used to examine modulation of one-time series by another, or modulation of one frequency by another within the same time series. These figures are made by the average of Figs $7(\mathrm{~b}), 8(\mathrm{~b})$ and $9(\mathrm{~b})$ over all scales between 8 and 14 months. By this it gives a measure of the average year variance versus time. The variance plot shows some distinct periods when monthly rainfall variance of average rainfall in the northwestern region was low in Fig. 7(d), e.g., from 2006 to 2014. These are the dry years and there is no important peak in the scale average time series. When in this fig. 7(d), the years 1984, 1987, 1998, 1999, 2004, 2005 indicating wetter than the normal years. Monthly 
rainfall variance in Rangpur station was low in Fig. 8(d), e.g. from 2006-2014. These are the dry years and an important peak in the scaleaverage time series can be identified for 1984 to 1987 , which clearly indicating a period wetter than normal years. Monthly rainfall variance in Dinajpur station was low in Fig. 9(d), e.g. from 2006-2016. These are the dry years and an important peak in the scale-average time series can be identified for 1987, which clearly indicating a year wetter than normal years.

Santos et al., (2001) analyzed scale average time series for the 8-16 months band. This gives a measure of the average year variance versus time. In the present study a measure of the average year variance versus time is done for the 8-14 months band. The variability of monthly rainfall time series is analyzed for the northwestern region by wavelet analysis. The wavelet power spectrum shows a big power concentration between the 8-14 months band. It shows that rainfall variability occurs from station to station. The distribution of rainfall is uneven.

\subsection{Relationship between rainfall and ground water level}

Groundwater in Bangladesh occurs at a very shallow depth. The groundwater table over most of the Bangladesh lies in very close to the surface and it fluctuates with the annual recharge discharge conditions. In the northwestern region, Bangladesh irrigation accounts for more than $70 \%$ of total water withdrawals and for more than $90 \%$ of total consumptive water use. This lead ground water depletion and increase drought condition (Adhikari et al., 2013). There is a relationship between rainfall and ground water level. Pearson correlation, MK test and time series are used to reveal the relationship between rainfall and ground water level. The relationship between rainfall and ground water level is discussed here-

\subsubsection{Correlation between rainfall and ground water level}

In this study, the annual and seasonal ground water level data of 5 districts of northwestern region for the period of 1981-2014 have been analyzed to find out the relationship of it with the rainfall. Table 2 shows the Pearson correlation between rainfall and ground water level of the northwestern region, Bangladesh for the period of $\quad 1981-2014$.

From the Table 2 it is seen that all the correlations are negative and significant at $1 \%$ and $5 \%$ level. In annual correlation, $r$ value is .570 which is strongly negative significant. In pre-monsoon season correlation, $r$ value is $\quad-.475$ which is strongly negative significant. In monsoon season correlation, $r$ value is -.430 which is negatively significant. In post-monsoon season correlation, $r$ value is -.470 which is strongly negative significant and in winter season correlation, $r$ value is -.372 which is negatively significant. There is a negative relationship between rainfall and ground water level. That means when rainfall increases the ground water level depth is decreased. When rainfall decreases the ground water level depth is increased. This indicates that when rainfall decreased the ground water level declined and when rainfall increased the ground water level was not declined. From Table 2 the correlation of annual, pre-monsoon and postmonsoon rainfall and ground water level are negative and significant at the $99 \%$ level. Correlation of monsoon and winter season is also negative and significant at the $95 \%$ level. So it is seen that when the rainfall decrease, the ground water level depth increase and when the rainfall increase, the ground water level depth decrease.

Table 2: Pearson correlation between rainfall and groundwater level.

\begin{tabular}{cc}
\hline Annual and Seasons & $\begin{array}{c}\text { r Value of Pearson Correlation between Rainfall and } \\
\text { Ground Water Level }\end{array}$ \\
Pre-monsoon & $-.570^{* *}$ \\
Monsoon & $-.475^{* *}$ \\
Post-monsoon & $-.430^{*}$ \\
Winter & $-.470^{* *}$ \\
\hline
\end{tabular}

** Correlation is significant at the $99 \%$ level

* Correlation is significant at the $95 \%$ level 


\subsubsection{Relationship analysis between rainfall and ground water level trends}

The Table 3 shows the MK test $Z$ values of annual and seasonal rainfall for the period of 1976-2016 and ground water table depth for the period of 1981-2014 in the northwestern region, Bangladesh to explain the relationship. From the Table 3 it is seen that in the annual rainfall the highest decreasing trend was found in Rajshahi $(-2.9765 \mathrm{~mm} / \mathrm{year})$ and in the annual ground water level depth the highest increasing trend was found in Rajshahi $(6.4338 \mathrm{~m} / \mathrm{year})$. That means Rajshahi had the highest depleted rate at the annual ground water level. One interesting finding is observed that there was a significantly high decreasing trend in annual rainfall in Rangpur (-2.280 $\mathrm{mm} / \mathrm{year}$ ) but the annual ground water level depth in Rangpur was less increasing which was significance at the $95 \%$ level. In the pre-monsoon season the highest decreasing trend of rainfall was found in Pabna $(-2.2915 \mathrm{~mm} / \mathrm{year})$ and in the ground water level depth the highest increasing trend was found in Rajshahi $(6.9971 \mathrm{~m})$. Also Pabna had high increasing trend in ground water level depth $(5.0403 \mathrm{~m})$. In the monsoon season the highest decreasing trend of rainfall was found in Rajshahi $(-2.5386 \mathrm{~mm} / \mathrm{year})$ and in the ground water level depth the highest increasing trend was found in Rajshahi $(5.3961 \mathrm{~m})$. In the post-monsoon season the highest decreasing trend of rainfall was found in Rajshahi (-1.303 mm/year) and in the ground water level depth the highest increasing trend was found in Rajshahi (5.3072 $\mathrm{m}$ ). In the winter season the highest decreasing trend of rainfall was found in Rajshahi $(-1.7207 \mathrm{~mm} /$ year) and in the ground water level depth the highest increasing trend was found in Rajshahi $(6.8192 \mathrm{~m})$. It is found that the Rajshahi district had decreased in the rainfall and for this the ground water level also depleted.

Table 3: Z Statistic values of seasonal and annual rainfall for the period of 1976-2016 and ground water level depth for the period of $1981-2014$ using the MK test for the northwestern region.

\begin{tabular}{|c|c|c|c|c|c|c|c|}
\hline \multirow[t]{2}{*}{ Districts } & \multicolumn{2}{|c|}{ Pre-monsoon } & \multicolumn{3}{|c|}{ Monsoon } & \multicolumn{2}{|c|}{ Post-monsoon } \\
\hline & Rainfall & $\begin{array}{c}\text { Ground water } \\
\text { level depth }\end{array}$ & Rainfall & & & Rainfall & $\begin{array}{l}\text { Ground water } \\
\text { level depth }\end{array}$ \\
\hline Rangpur & 0.0449 & 4.0322 & -1.5163 & & & 0.1460 & 4.6213 \\
\hline Dinajpur & -0.2452 & 6.1966 & $\begin{array}{l}-1.1578 \\
\end{array}$ & & & -0.5584 & 5.2182 \\
\hline Bogra & -1.010 & 5.218 & $-1.9207^{a}$ & & & -1.1346 & 4.5659 \\
\hline Rajshahi & -0.1460 & 6.9971 & $-2.5386^{b}$ & & & -1.303 & 5.3072 \\
\hline Pabna & $-2.2915^{a}$ & 5.0403 & -1.6511 & & & 0.4269 & 3.7654 \\
\hline \multirow{2}{*}{\multicolumn{2}{|c|}{ Districts }} & \multicolumn{3}{|c|}{ Winter } & \multicolumn{3}{|c|}{ Annual } \\
\hline & & Rainfall & \multicolumn{2}{|c|}{$\begin{array}{l}\text { Ground water } \\
\text { level depth }\end{array}$} & \multicolumn{2}{|c|}{ Rainfall } & $\begin{array}{l}\text { Ground water } \\
\text { level depth }\end{array}$ \\
\hline Rangpur & & -0.1574 & \multicolumn{2}{|c|}{1.4528} & \multicolumn{2}{|c|}{$-2.2801^{a}$} & $2.0754^{a}$ \\
\hline Dinajpur & & -1.6232 & \multicolumn{2}{|c|}{6.1077} & \multicolumn{2}{|c|}{-1.8116} & 5.6629 \\
\hline Bogra & & -0.4724 & \multicolumn{2}{|c|}{6.5228} & \multicolumn{2}{|c|}{$-2.1902^{a}$} & 5.574 \\
\hline Rajshahi & & -1.7207 & \multicolumn{2}{|c|}{6.8192} & \multicolumn{2}{|c|}{$-2.9765^{b}$} & 6.4338 \\
\hline Pabna & & -0.8886 & \multicolumn{2}{|c|}{5.3368} & \multicolumn{2}{|c|}{$-2.0330^{a}$} & 4.9514 \\
\hline
\end{tabular}

a Significance at the $95 \%$ level and ${ }^{\mathrm{b}}$ Significance at the $99 \%$ level

Table 3 shows that the districts which have high decreasing trend in rainfall have high increasing trend in ground water level depth. The districts which have less decreasing trend in rainfall have less increasing trend in ground water level depth. But in case of annual rainfall and ground water level trend for Rangpur, there is a different finding is observed. Here the annual rainfall trend is decreasing significantly in Rangpur but the annual ground water level trend is less declined. However, the ground water level is depleted more in those districts which have highest decreasing rainfall trend. Pre-monsoon and winter season receives less rainfall and thus the ground water level depletion occurs more in those seasons than other seasons. When rainfall decreased, the ground water level depth increased that means ground water level depleted in this region and when rainfall increased, the ground water level depth decreased that means ground water level increased. So there is a strong relationship between rainfall and ground water level.

Shalini et al., (2012) analyzed the ground water level and rainfall variability trend in Jharkhand State, India. They mentioned that the regions which receive less rainfall have a deeper ground water level than others. Their analysis agrees with my analysis. Thakur et al., (2011) mentioned that in the pre-monsoon and winter season had decreased in rainfall and for that the ground water level depleted more in those seasons. Their analysis is consistent with the present study. 
3.4.3 Relationship analysis between rainfall and ground water level time series

Time series of the relationship between mean rainfall and mean ground water level are shown respectively in figures. Figure 10(a) shows the mean annual rainfall and ground water level time series and Figure 10(b), 10(c), 10(d) and 10(e) show the mean seasonal (premonsoon, monsoon, post-monsoon and winter) time series of the northwestern region during the 1981-2014. All the time series figures show that the trend of rainfall is decreasing and the trend of ground water level depth is increasing. That indicates that rainfall is decreasing and for this ground water level is declining in the northwestern region. Pre-monsoon and winter season have decreased in rainfall more and for that the ground water level depleted more in those seasons. For decreasing rainfall and increasing use of ground water in irrigation and other purposes, the ground water level in the northwestern region is depleting. Especially in winter and pre-monsoon season drought condition may occur. That makes this region more prone to drought condition.
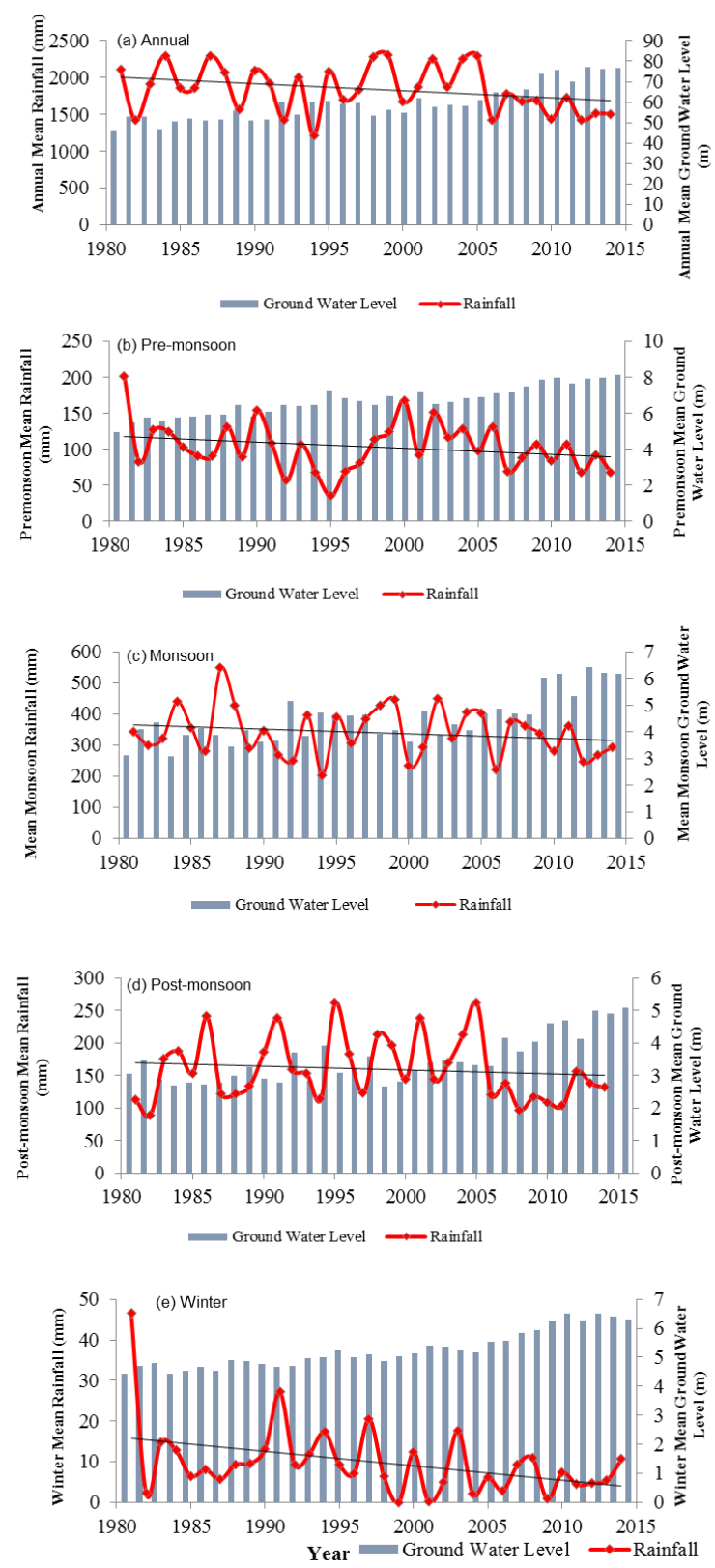

Figure 10: Time series of annual and seasonal mean rainfall and ground water level. 
Ambeast et al., (2006) investigated on management of declining ground water, India and found that ground water levels are declining with respect to the ground surface. All the seasons have a declining trend of ground water level. This finding is consistent with the present study. Northwestern region faces decrease in rainfall mostly from the last decade. Decrease in rainfall leads decrease in ground water level. That is the main cause of ground water depletion (Adham et al., 2010). Due to decrease in rainfall, ground water recharge is also decreased. For this ground water depletion occurs. Decrease in rainfall increase the withdrawal of ground water that is used for irrigation purpose. That is the main cause of ground water depletion in this region (Adhikari et al., 2013). In Bangladesh, large scale of withdrawal of ground water is one of the main causes of ground water depletion.

\section{Conclusion}

This study aims to explore the spatiotemporal variability and trends of rainfall link to groundwater level in the northwestern region, Bangladesh. The results reveal wide variations of rainfall for both annual and seasonal time scales. The findings also reveal that the highest standard deviation was found in Rangpur $(583.56 \mathrm{~mm})$ followed by Syedpur $(502.71 \mathrm{~mm})$, which showed that there is high variability of rainfall received annually. All the meteorological stations showed positive skewness, which indicates that the amount of rainfall distribution was normal. The annual rainfall variability was the highest in the Ishwardi station (25.39\%) where the lowest annual rainfall variability found in Rajshahi $(20.70 \%)$. Due to climate change the rainfall is decreasing in recent years and the sharp decreasing trend of rainfall over northwestern region may be the key or one cause for the decreasing trend of rainfall over the whole Bangladesh. The study observes that all the stations show a negative or decreasing trend in annual rainfall in which Rajshahi, Rangpur and Bogra districts have a significant negative trend. In addition, the monsoon and the winter season represents decreasing trends of rainfall for all the stations. The wavelet analysis of rainfall time series demonstrates that there is a variation in rainfall at district level. The monthly rainfall variance of average rainfall in the northwestern region was low from the period of 2006 to 2014. These are the dry years and there is no significant peak in the average time series. The years 1984, 1987, 1998, 1999, 2004, 2005 are wetter than the normal years. In Bangladesh, the rainfall variability occurs due to the effects of climate change. Due to global warming, climate change occurs and the temperature of Bangladesh is increasing and thus the rainfall distribution is becoming more uneven. The rainfall variability occurs over Bangladesh including the northwestern region. The relationship between rainfall and ground water level indicates that rainfall is decreasing and for this ground water level is declining in the northwestern region. Pre-monsoon and winter season have decreased in rainfall more and for that the ground water level depleted more in those seasons. Interestingly, it is observed that a significant high decreasing trend of annual rainfall is found in Rangpur, but the annual groundwater level depth is less increased in Rangpur at the same time. Decrease in rainfall increases the withdrawal of ground water that is used for irrigation purpose. The Government of Bangladesh should take necessary measures to save this region from becoming a barren region. Proper steps should take to combat climate change and proper policy should adopt in the case of groundwater exploitation for irrigation purpose.

\section{References}

Ahasan, M.N., Chowdhary, M. A. and Quadir, D.A. 2010. Variability and trends of summer monsoon rainfall over Bangladesh. J.Hydrol.Meteorol. 7(1):1-17

Adhikary, S.K., Das, S.K., Saha, G.C. and Chaki, T. 2013. Groundwater Drought Assessment for Barind Irrigation. In: 20th International Congress on Modeling and Simulation.

Ahmed, A.S.M.S., Munim, A.A., Begum, Q.N. and Choudhury, A.M. 1996. El Niño southern oscillation and rainfall variation over Bangladesh.Mausam 47(2):157-162

Ahmed, R. and Kim, I.K. 2003. Patterns of daily rainfall in Bangladesh during the summer monsoon season: case studies at three stations. Phys. Geogr. 24(4):295-318

Ahammed, F., Hewa, G.A. and Argue, J.R. 2014. Variability of annual daily maximum rainfall of Dhaka, Bangladesh. Atmos. Res. 137, 176-182. http://dx.doi.org/10.1016/j.atmosres.2013.10.013.

Agrawala, S., Ota, T., Ahmed, A.U., Smith, J., Van Aalst, M., 2003. Development and Climate Change in Bangladesh: Focus on Coastal Flooding and the Sundarbans (OECOD Fr).

Adham, M.I., C.S. Jahan, Q.H. Mazumder, M.M.A. Hossain and A.M. Haque. 2010. Study on Groundwater Recharge Potentiality of Barind Tract, Rajshahi District, Bangladesh Using GIS and Remote Sensing Technique. J.Geo. Socie. India,75.

Ambast, S.K., Tyagi, N.K. and Raul, S.K. 2006. Management of declining groundwater in the Trans Indo-Gangetic Plain (India): some options. Agric. Water Manag., 82: 279-296.

Briffa, K.R., van der Schrier, G., Jones, P.D., 2009. Wet and dry summers in Europe since 1750: evidence of increasing drought. Int. J. Climatol. 29, 1894-1905. http://dx.doi.org/10.1002/joc.1836.

Banglapedia, 2003.National Encyclopedia of Bangladesh.Asiatic Society of Bangladesh, Dhaka.

Bari, S.H., Rahman, M.T., Hoque, M.A. and Hussain, M.M. 2016. Analysis of seasonal and annual rainfall trends in the northern region of Bangladesh. J.Atmos. Res. 176-177: 148-158.

Bari, M.F. and Anwar, A.H.M.F. 2000.Effects on irrigated agriculture on ground water quality in northwestern Bangladesh. In: Proceedings of Integrated Water Resources Management for Sustainable Development, New Delhi, 119-121 pp. BDWS, 2005. Bangladesh drinking water standard, Dhaka, Bangladesh.

BADC (Bangladesh Agricultural Development Corporation), 2005. Minor Irrigation Survey Report of 2005, BADC, Bangladesh. 
Choudhury, S.A., Terao, T., Murata, F., Hayashi, T., 2013.Seasonal variations of temperature and rainfall characteristics in the northeastern part of Bangladesh around Sylhet. J. Agrofor. Env. 6: 25-40

Choudhury, B.U., Das, A., Ngachan, S.V., Slong, A., Bordoloi, L.J., Chowdhury, P., 2012. Trend analysis of long term weather variables in mid altitude Meghalaya, North-East India. J. Agric. Phys. 12: 12-22.

Choudhury, A.M., Quadir, D.A., Neelormi, S., and Ahmed, A.U., 2003. Climate Change and Its Impacts onWater Resources of Bangladesh, in A. Muhammed(ed.), Climate Change and water Resources in South Asia, Asianics Agro Dev International, Islamabad, 21-60 pp.

Fatima Denton TW, 2013. Climate-resilient pathways: adaptation, mitigation, and sustainable development. In: Bhadwal S (edn) IPCC, Fifth Assessment Report.

Hossain, M.S. and Roy, K. 2010. Rainfall Variability over the South Coast of Bangladesh.In Proceedings of International Conference on Bangladesh Environment 2010 by BEN and BAPA, Dhaka, Bangladesh, 3-4 January 2009.

Islam, M.N. 2009. Rainfall and temperature scenario for Bangladesh. Open. Atmos. Sci. J. 3:93-103

Ideiao, S.M. and Santos, C.A. 2005.Analysis of Precipitation Time Series Using The Wavelet Transform. Sociedade\&Natureza, Uberlândia, Special Issue, 736-745 pp.

IPCC, 2007 Climate change 2007: impacts, adaptation and vulnerability. In: Parry ML, Canziani OF, Palutikof JP, van der Linden PJ, Hanson CE (eds) Contribution of working group II to the fourth assessment report of the intergovernmental panel on climate change. Cambridge University Press, Cambridge.

Kozak, M. 2008. Correlation coefficient and the fallacy of statistical hypothesis testing.Curr. Sci. 95(9): 1121-1122.

Khan, F.K. 2015. Pakistan geography, economy and people, 4th edn. Oxford University Press, Pakistan.

Lu, G.Y. and Wong, D.W. 2008.An adaptive inverse-distance weighting spatial interpolation technique. Comp.Geosc. J. 34 (9): 10441055.

Mirza, M.Q., Warrick, R.A., Ericksen, N.J. and Kenny, G.J. 2010.Trends and persistence in precipitation in the Ganges, Brahmaputra and Meghna river basins. Hydrol. Sci. 43: 845-858.

Meshram, S.G., Singh, V. and Meshram, C. 2016.Long-term trend and variability of precipitation in Chhattisgarh State, India.Theor. Appl.Climatol., DOI 10.1007/s00704-016-1804-z

Rahman, G., Rahman, A., Samiullah and Dawood, M. 2018. Spatial and temporal variation of rainfall and drought in Khyber Pakhtunkhwa Province of Pakistan during 1971-2015.Arab. J. Geos.11:46. https://doi.org/10.1007/s12517-018-3396-7

Rahman, M.A., Yunsheng, L. and Sultana, N. 2016.Analysis and prediction of rainfall trends over Bangladesh using Mann-Kendall, Spearman's rho tests and ARIMA model. Springer-Verlag.Wien, DOI 10.1007/s00703-016-0479-4

Rahman, M.A., Kamal, S.M. and Billah, M. 2016. Rainfall Variability and Linear Trend Models on North-West Part of Bangladesh for the Last 40 Years. Amer.J.App. Math.4(3): 158-162; DOI: 10.11648/j.ajam.20160403.16

Rahman, K.M., Ahmed, F.R. and Islam, M. N. 2016. Modeling on climate induced drought of north-western region, Bangladesh. Springer International Publishing Switzerland, 2:45; DOI 10.1007/s40808-016-0089-7

Rahman, R. and Lateh, H. 2015. Climate change in Bangladesh: a spatiotemporal analysis and simulation of recent temperature and rainfall data using GIS and time series analysis model. Theor. Appl.Climatol. DOI:10.1007/s00704-015-1688-3

Rajeevan,M., Bhate, J. Jaswal, A.K. 2008. Analysis of variability and trends of extreme rainfall events over India using 104 years of gridded daily rainfall data. Geop. Res.Lett. 35:L18707. DOI:10.1029/2008GL035143

Shahid, S. and Behrawan, H. 2008. Drought risk assessment in the western part of Bangladesh, Nat. Hazard, 46: 391-413.

Sarkar, A.A., Ali, M.H. 2009. Water-table dynamics of Dhaka city and its long-term trend analysis using the "MAKESENS" model. Water Int. 34(3):373-382.

Shahid, S. 2010. Rainfall variability and the trends of wet and dry periods in Bangladesh. Int. J.Climatol. 30(15):2299-2313. DOI:10.1002/joc.2053

Solomon, S., Qin, D., Manning, M., Chen, Z., Marquis, M., Averyt, K.B., Tignor, M. and Miller, H.L. (eds) Climate Change 2007: the physical science basis. Contribution of Working Group I to the fourth assessment report of the Intergovernmental Panel on Climate Change. Cambridge University Press, Cambridge, 21-91pp.

Santos, C.A.G., Galvão, C.O., Suzuki, K. \&Trigo, R.M. 2001. Matsuyama city rainfall data analysis using wavelet transform, Ann. J. Hydraul. Engng, JSCE, 45:211-216.

Shalini, T.A., Pandey, A.C. and Nathawat, M.S. 2012. Groundwater Level and Rainfall Variability Trend Analysis using GIS in parts of Jharkhand state (India) for Sustainable Management of Water Resources. Department of Remote Sensing, Birla Institute of Technology, Mesra, Ranchi-835215, Jharkhand, INDIA.1(4):24-31.

Torrence, C. \& Compo, G.P. 1998.A practical guide to wavelet analysis.Bull. Am. Met. Soc., 79(1): 61-78.

Teyso, T.A. and Anjulo, A. 2016.Spatio-temporal Variability and Trends of Rainfall and Temperature Over GamoGofa Zone, Ethiopia.Directorate of Climate Change Research, Ethiopian Environment and Forest Research Institute; DOI: 10.9734/JSRR/2016/28667

Thakur, G.S. and Thomas, T. 2011. Analysis of Groundwater levels for Detection of Trend in Sagar District, Madhya Pradesh. Jour. Geol. Soc. India. 77:303-308.

Ye, Z. and Li, Z. 2017.Spatiotemporal Variability and Trends of Extreme Precipitation in the Huaihe River Basin, a Climatic Transitional Zone in East China. Adv. Meteo. J. DOI:10.1155/2017/3197435

Zhang, Q., Xu, C.-Y., Zhang, Z., 2009. Observed changes of drought/wetness episodes in the Pearl River basin, China, using the standardized precipitation index and aridity index. Theor. Appl. Climatol. 98, 89-99. http://dx.doi.org/10.1007/s00704-008-0095-4. 